\title{
A NOVEL EXERCISE DEVICE FOR USERS IN WHEELCHAIRS: A STUDY OF ABDOMINAL MUSCLE ACTIVATION
}

\author{
A Thesis presented to \\ The Faculty of \\ California Polytechnic State University, \\ San Luis Obispo
}

\author{
In Partial Fulfillment \\ Of the Requirements for the Degree \\ Master of Science in Biomedical Engineering \\ By \\ Rebecca Jo Campbell \\ June 2011
}


(C) 2011

Rebecca Jo Campbell

ALL RIGHTS RESERVED 


\section{COMMITTEE MEMBERSHIP}

TITLE:

AUTHOR:

DATE SUBMITTED:

COMMITTEE CHAIR:

COMMITTEE MEMBER:

COMMITTEE MEMBER:
A Novel Exercise Device for Users in Wheelchairs: A Study of Abdominal Muscle Activation

Rebecca Jo Campbell

June 2011

Dr. Lily Laiho

Dr. Trevor Cardinal

Dr. Dan Walsh 


\begin{abstract}
A Novel Exercise Device for Users in Wheelchairs: A Study of Abdominal Muscle Activation

\section{Rebecca Jo Campbell}

This study evaluates the use of a wheelchair balance board. The balance board was created as a sensory stimulation tool for users with various disabilities. It was originally designed to create vestibular stimulation for the person after they were loaded on. This study was used as a way to test if the balance board could be used for other things such as physical therapy and exercise. Ten able-bodied individuals were used to show the functionality of the device. They were asked to perform six different abdominal exercises while the muscle activity of their rectus abdominis and external obliques was measured using EMG electrodes. The exercises performed included: abdominal crunch, reverse crunch, full vertical crunch, torso twist, seated crunch, and sitting abdominal bend down. The last three exercises were performed on both stable ground and on the wheelchair balance board. This study found that the balance board did not cause any negative effects in terms of the abdominal muscle activation. In some cases it actually increased the muscle activation compared to the stable and floor exercises. There were no cases where the balance board caused a decrease in the amount of muscle activation in comparison to the floor exercises. The highest values for any muscle group activated in the entire study was found to be on the balance board during the sitting abdominal bend down. This demonstrates that the balance board shows promise as a tool for stimulating muscles not traditionally activated for people in a wheelchair.

Keywords: Unstable platform, EMG, abdominal exercise, wheelchair 


\section{ACKNOWLEDGMENTS}

I would like to first thank all those who participated in my study. Without them I would not have been able to complete this project. I would like to give a special thanks to Ian Mahaffey and Zachary Tiulentino for being on the original wheelchair balance board design team. Without them the balance board would not have gone from on paper into reality so thanks guys. I would also like to thank my committee members Professor Walsh and Professor Cardinal as well as my advisor Professor Laiho. These faculty members have been supportive and helpful not only during my thesis work but throughout my time here at Cal Poly.

Professor Walsh is one of the most supportive people I know and is always willing to help no matter the request. He has made my years here at Cal Poly truly enjoyable and ones that I will never forget. From Segways in class to inspirational talks he has played a key role in my education here and I would not be where I am today without him.

Professor Cardinal played a key role in assisting me with my project as well as in my classes along the way. He was always willing to meet with me to help, on his time outside of office hours as needed. even with everything he had going on. He played a key role in helping me to source information and programs from AD Instruments as well as to understand the key parts of designing an experiment. Professor Cardinal has always pushed me to not learn things just for a test, but to learn it so that I will remember it in the future. 
Finally I would like to thank Professor Laiho for everything she has done. She has been very supportive and always enthusiastic about the wheelchair balance board during the design and manufacturing as well as during testing and the follow up study. Not only is she supportive with this project but she has helped me in many other ways from picking classes to providing tips on interviewing. Without her help and support I would not have been able to finish this project or be where I am today.

Thanks again to everyone who has helped on this project in any way. Without you it would not have been possible. 
Table of Contents

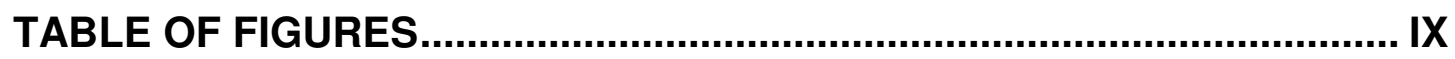

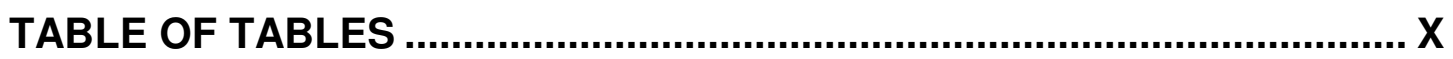

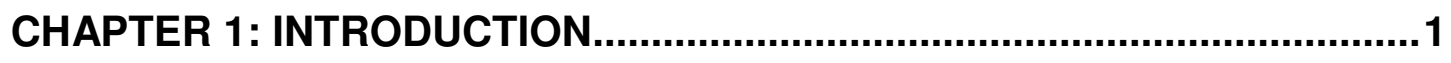

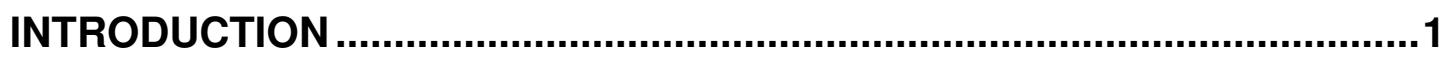

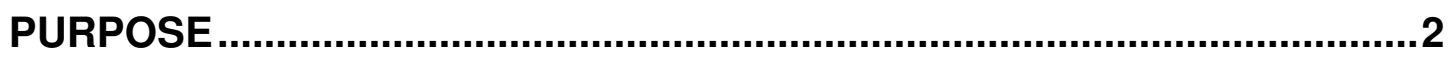

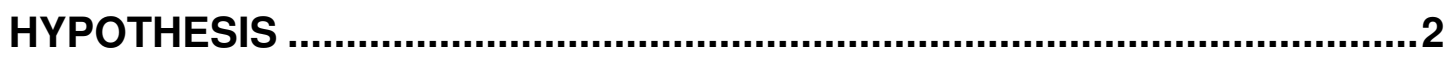

BACKGROUND OF WHEELCHAIR BALANCE BOARD.............................2

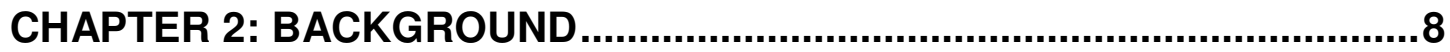

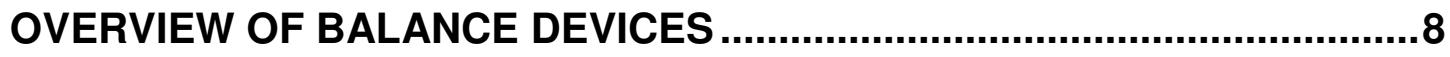

EFFECTS OF BALANCE BOARD TRAINING ............................................ 11

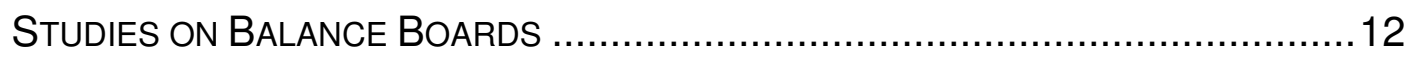

Studies on Core muscles................................................................ 12

Studies on The Ankle ............................................................... 15

CANADIAN SOCIETY FOR EXERCISE PHYSIOLOGY .................................. 16

ELECTROMYOGRAPHY ....................................................................18

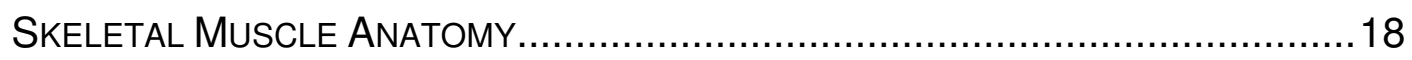

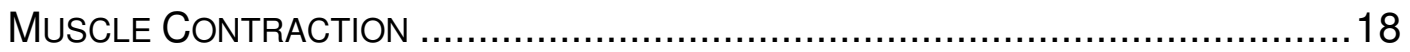

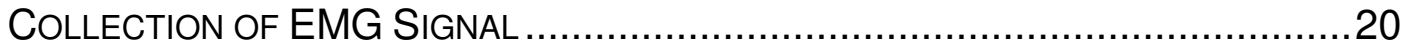

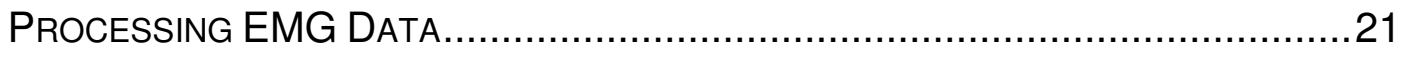

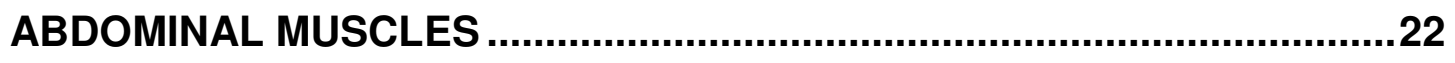

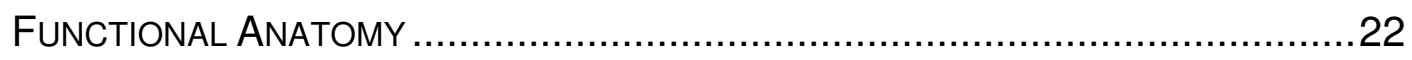

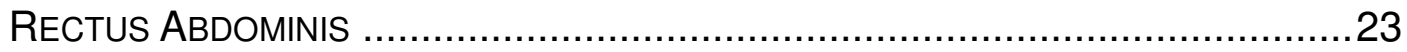

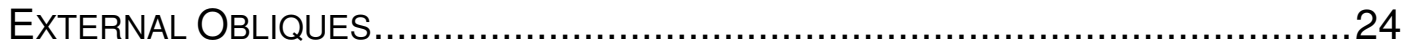

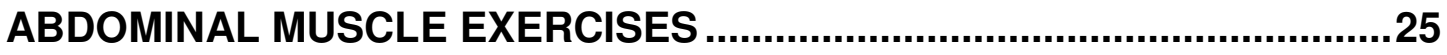

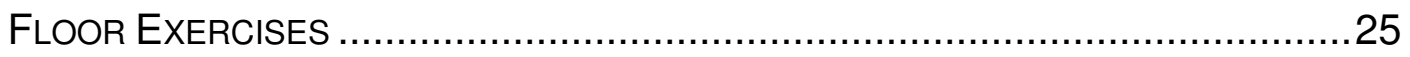

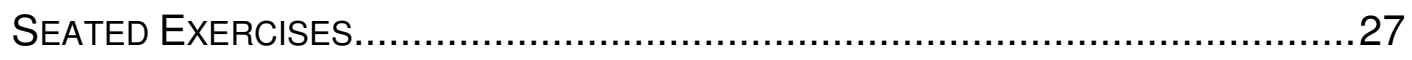

CHAPTER 3: METHODS ..........................................................................

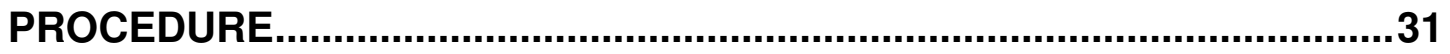

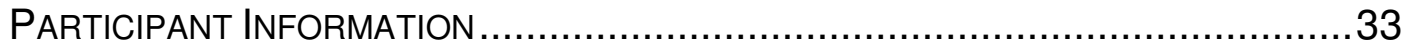

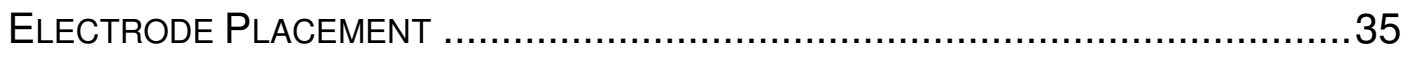

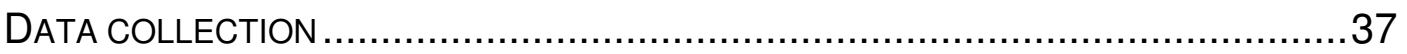

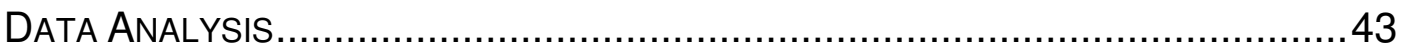

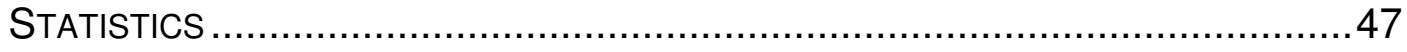

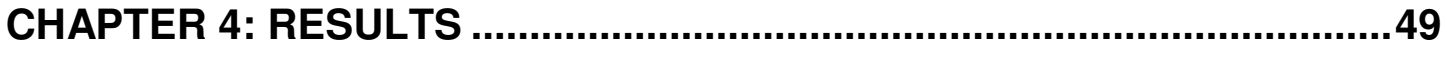

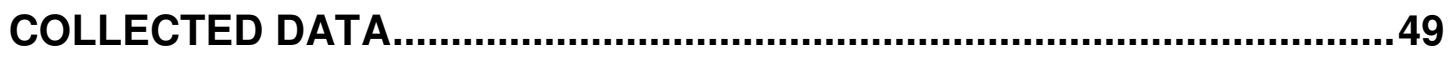




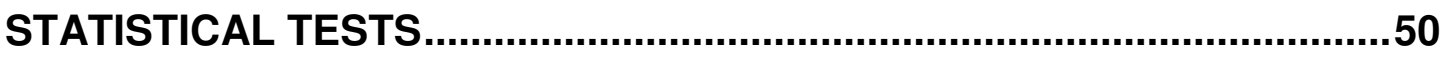

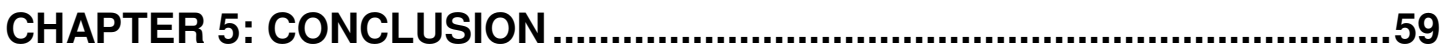

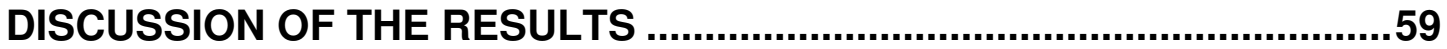

SUMMARY

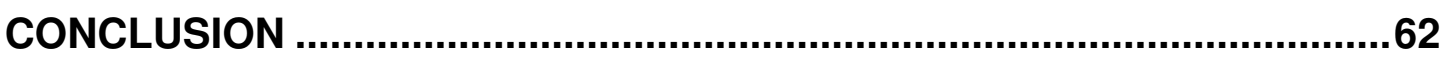

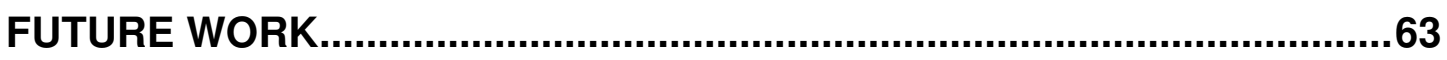

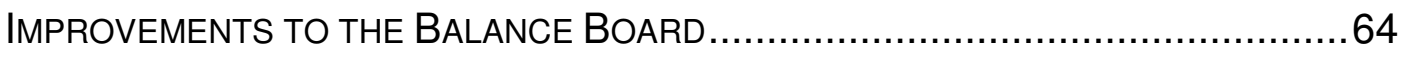

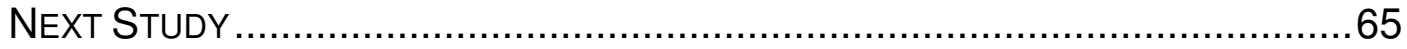

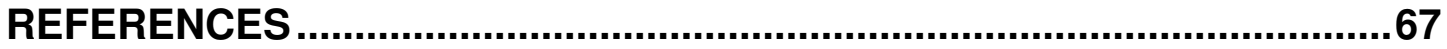

APPENDIX A

HUMAN SUBJECTS PROTOCOL..........................................................

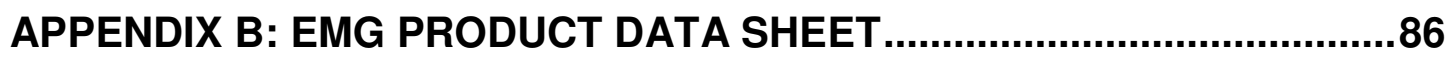

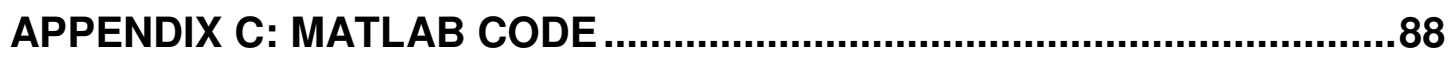

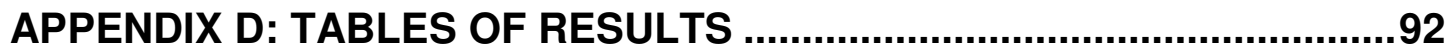




\section{Table of Figures}

FIGURE 1: WHEELCHAIR BALANCE BOARD CONCEPTUAL DESIGN IN SOLID WORKS. ..4

FIGURE 2: WHEELCHAIR BALANCE BOARD PLATFORM SPECIFICATIONS .................1

FIGURE 3: EXPLODED VIEW OF BALANCE BOARD COMPONENTS ......................... 1

FIGURE 4: INSTABILITY DEVICES ON THE MARKET …....................................

FIGURE 5: MUSCLE FIBER [3] ..........................................................

FIGURE 6: EMG SIGNAL CONVERTED TO RMS …......................................21

Figure 7: ERECTOR SPINAE Group and Abdominal Muscle ANATOMy [4], [7] ...1

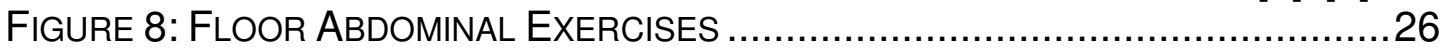

FIGURE 9: SEATED ABDOMINAL EXERCISES …........................................

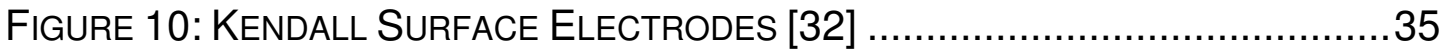

FIGURE 11: ELECTRODE PLACEMENT ……............................................

FIGURE 12: MODIFIED BALANCE BOARD EXERCISES ....................................

FIGURE 13: DATA ANALYSIS FLOWCHART ..............................................

Figure 14: Individual Value Plots of the Percent Change From Baseline51

FIGURE 15: ANOVA TEST OF MUSCLE ACTIVATION.....................................5

Figure 16: SEATEd CRUNCH Right OBLIQUe ANd FlOOR EXERCISE RIGHT OBLIQUe PERCENT ChANGE FROM BASELINE .........................................56

Figure 17: Seated Abdominal Bend Down Right Oblique's Percent Change

Figure 18: Seated Abdominal Bend Down Upper Rectus Abdominis Percent CHANGE. 


\section{Table of Tables}

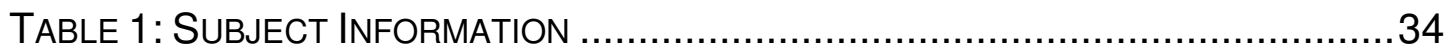

Table 2: Average Percent Change from Baseline for All 10 SubJects (\%) 


\section{Chapter 1: Introduction}

\section{Introduction}

This study evaluates the use of a wheelchair balance board during physical therapy and exercise routines. The balance board was designed during a senior design class to create vestibular stimulation for users with various cognitive ranges. The device is now being further tested to see what benefits it has on the abdominal muscles while performing various exercises.

Ten subjects participated in this study. The subjects had ten electrodes in total placed over their rectus abdominis, external obliques, and clavicle. Four electrodes were used to monitor the rectus abdominis, four were monitoring the external obliques, and two were used as grounds at the clavicle. The data was recorded using a PowerLab system and the computer program used was LabChart. The subjects started out by doing three traditional floor exercises, abdominal crunch, reverse crunch, and full vertical crunch. The subjects then performed three seated exercises on a stable chair, the seated crunch, torso twist, and seated abdominal bend down. These same three exercises were then performed on the wheel chair balance board to access the benefits of the board. The signal collected was an Electromyography (EMG) and this data was exported from LabChart into a notepad file. This file was then run through Matlab to gather the average muscle activation while the subject was performing a given exercise. These values were compared to the subject's baseline value as well as to their maximum contractile force to normalize them. A series of statistical tests were then performed on the data to determine if there was any significance. 


\section{Purpose}

The purpose of this study is to determine the benefit of using the wheelchair balance board on physical therapy and exercise for users in wheelchairs. If the balance board can create a higher muscle activation, it can lead to a faster recovery time from injury as well as keep users in better shape to improve their overall health. As of now, the only use the balance board has been used for has been sensory stimulation, so this study would also validate its use for other applications.

\section{Hypothesis}

For the study it is hypothesized that using an unstable platform during physical therapy and exercise will increase the abdominal muscle activation of the user compared to that seen on stable platforms. The hope is that after the study we will be able to recommend the balance board to users as a way to increase their core muscle activation.

\section{Background of Wheelchair Balance Board}

This study is working to determine the benefits of the wheelchair balance board. The balance board was created as a senior design project in a team of three people. The original design was to provide sensory stimulation to the user, but now the goal is to see if it can have benefits on other areas of the body.

The balance board was originally designed for users at VTC Enterprises. VTC Enterprises is located in Santa Maria, California and provides life skills training and aids in the care of people with both cognitive and physical disabilities. The original assignment was to create a device that would stimulate an individual's senses while

still being appropriate for adult users. There are many devices on the market today to 
create sensory stimulation however many are designed for children and are not appropriate for adult users. The design team took on the challenge to create an adult appropriate sensory stimulation device.

The vestibular sense was the sense that the device was designed for. This sense refers to the sensation of balance and tilt that most people who are not in wheelchairs use everyday when walking. For people in wheelchairs this sense is often overlooked so the balance board would create a novel sensation for most users.

The design process was used to develop the wheelchair balance board, with the final design shown in Figure 1. Many design requirements were taken into account to ensure that the device performed as needed and was safe for the users. The wheelchair balance board consists of a four-foot diameter wooden platform (Figure 2) made from two pieces of $3 / 4$ inch ACX plywood glued and bolted together. This type of wood has a parallel stress rating of 130MPa. The wood was cut from a four foot by eight foot sheet using a router, and the edges were rounded using a half inch round-over router bit. 


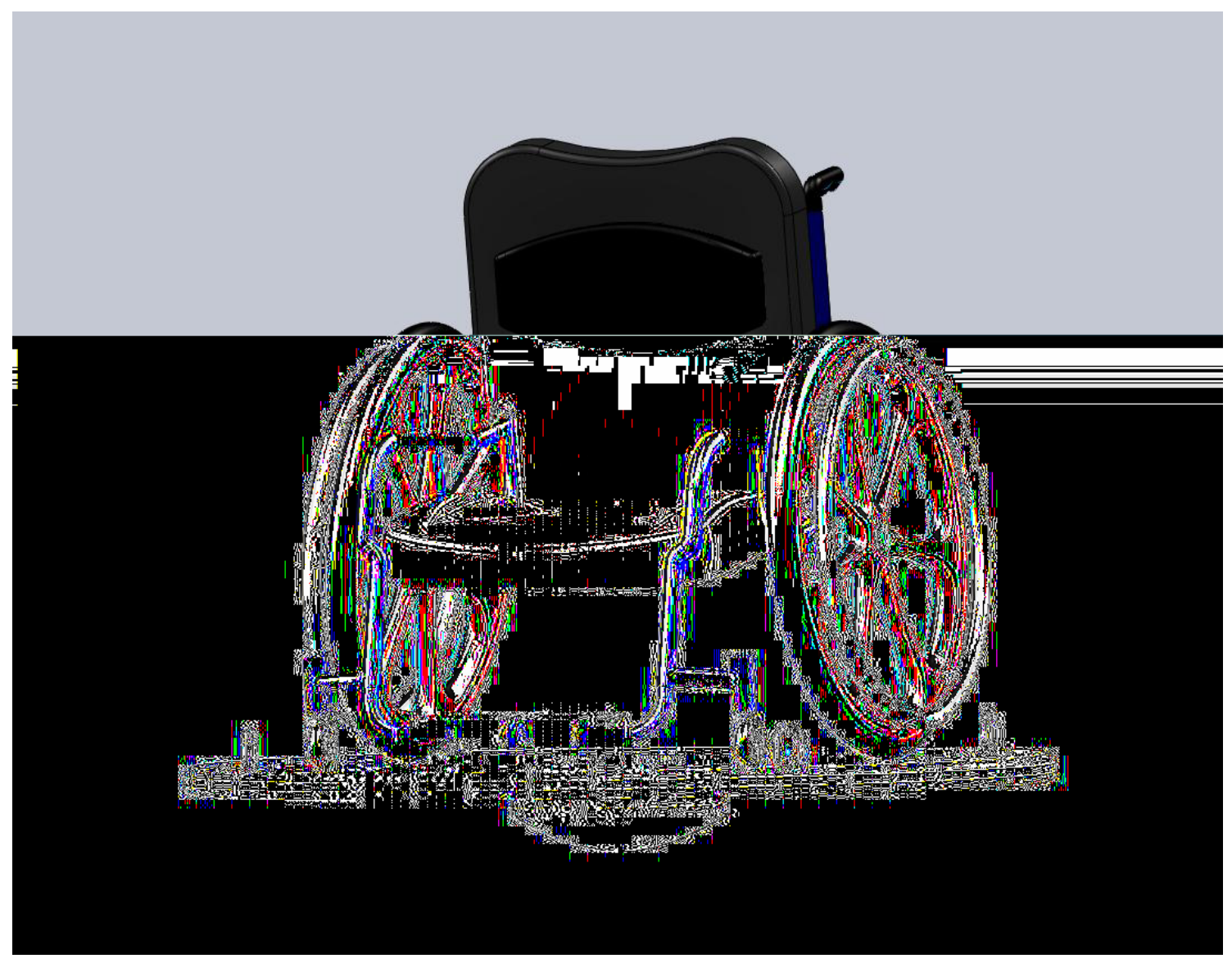

Figure 1: Wheelchair Balance Board conceptual design in solid works.

For the curvature on the bottom side of the wheelchair balance board, an actual balance board that is designed to stand on was used. It has a sixteen inch platform and is made from plastic. The purchased balance board was attached to the four foot diameter platform using five sixteenths inch hex bolts, washers, and nuts.

To attach the user's wheelchair to the balance board, four D-rings were used that had a four hundred pound working load each. These D-rings were attached to the board using one quarter inch round head slotted bolts, nuts, and washers. The location of the bolts were on the outer edge of the board acorn nuts were added to the bottom to keep them from hitting the ground. The tie-downs used are traditional ratchet tie downs that are used by the RTA buses in San Luis Obispo County. These have a 
ratcheting technology that will not allow the strap to slip once it has been tightened down. To make certain that the wheelchair wheels would not be able to slip on the balance board, X-Derm rubber was glued to the top of the platform in a three foot circle. Another piece of the rubber was placed under the board as a way to keep it from slipping on the ground. An exploded view of the balance board can be seen in Figure 3.

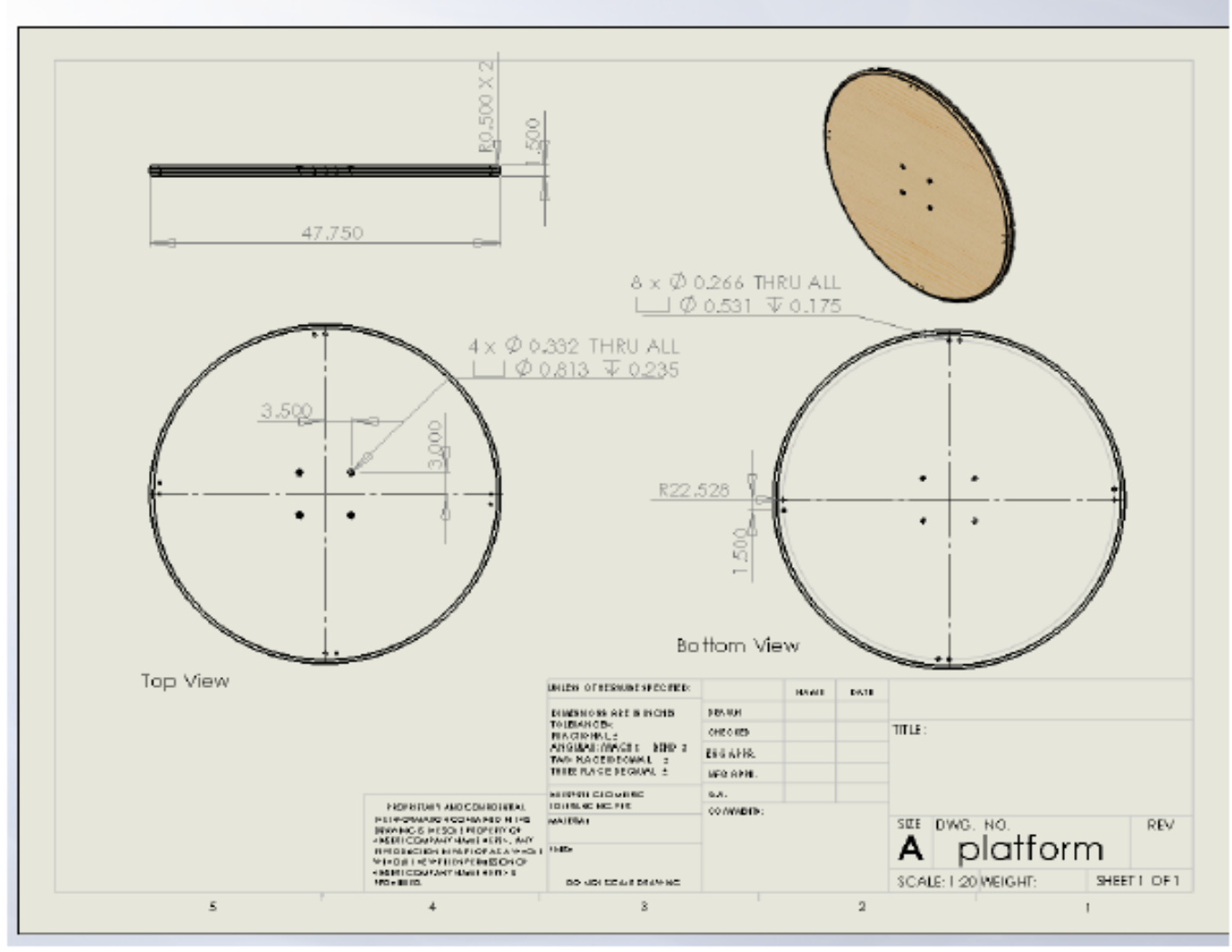

Figure 2: Wheelchair Balance Board Platform Specifications 
After everything is assembled, the user can be loaded onto the balance board and secured using the ratchet tie downs. The tie - down straps are secured onto the main frame of the wheel chair in four different locations to make sure there will be no loosening. After the chair is determined to be secure, the user can tip eight degrees in all directions.

The wheelchair balance board allows persons who use wheelchairs to receive vestibular stimulation similar to that of a person who would stand on a balance trainer device. Some of the users at VTC lack the day to day stimulation of their vestibular senses since they use wheelchair and do not need to use balance to move from one location to another. By creating a balance board that accommodates wheelchairs the device provided the opportunity for these uses to experience a sense that most people use every day. 

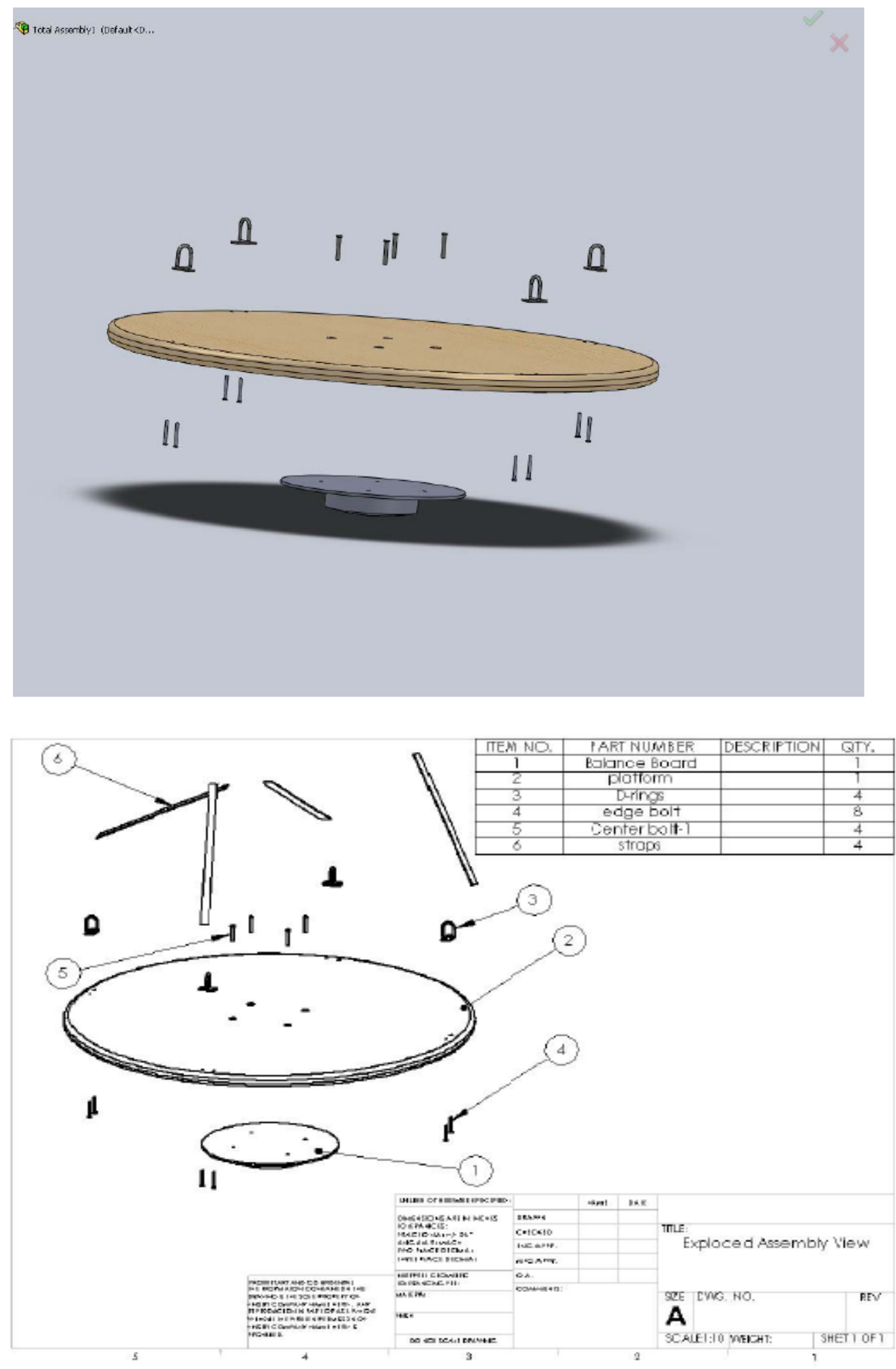

Figure 3: Exploded view of balance board components 


\section{Chapter 2: Background}

\section{Overview of Balance Devices}

Balance boards are common place in the world, and most people have an idea of what they are in their mind already. They are often used for physical rehabilitation of leg injuries, recreational use, and balance training. The boards typically are a simple design: either a board balances on a curved half dome surface or a roller, or have their own curved surface built in. The height of the board from the ground varies on the style and the degree of difficulty that people are trying to obtain. The balance board forces the user to use his or her balance skills to prevent the board from touching the ground on any sides, or can be used to increase range of motion by making the user touch the sides of the board to the ground in a certain sequence.

There are two main senses that the balance boards affect, the proprioception sense and the vestibular sense. These senses give our brain the information it needs in order to help us balance while using the various balance devices, along with everyday activities. The proprioception sense comes from signals that get sent to our brains from forces in our joints. This information lets us know where we are orientation wise as well as the movement of the different joints and parts of our body. The vestibular sense on the other hand controls our sense of movement and balance. It helps us to determine our heads position relative to the ground. When different signals are sent to the brain about how our body is positioned, it sends out signals to our different muscles to tell them to tighten and relax in order to keep us balanced. [10]. 
When a balance board is used, the person notices the small shifts in stability much more than when walking on stable ground. Their body is having to work and activate more muscles in order to adjust for all of the small movements that the balance board is making underneath them. Any small movement that the person makes can potentially be amplified with the board moving under them. Their body sends signals to the brain which then must activate more muscles in order to keep the person balanced [10].
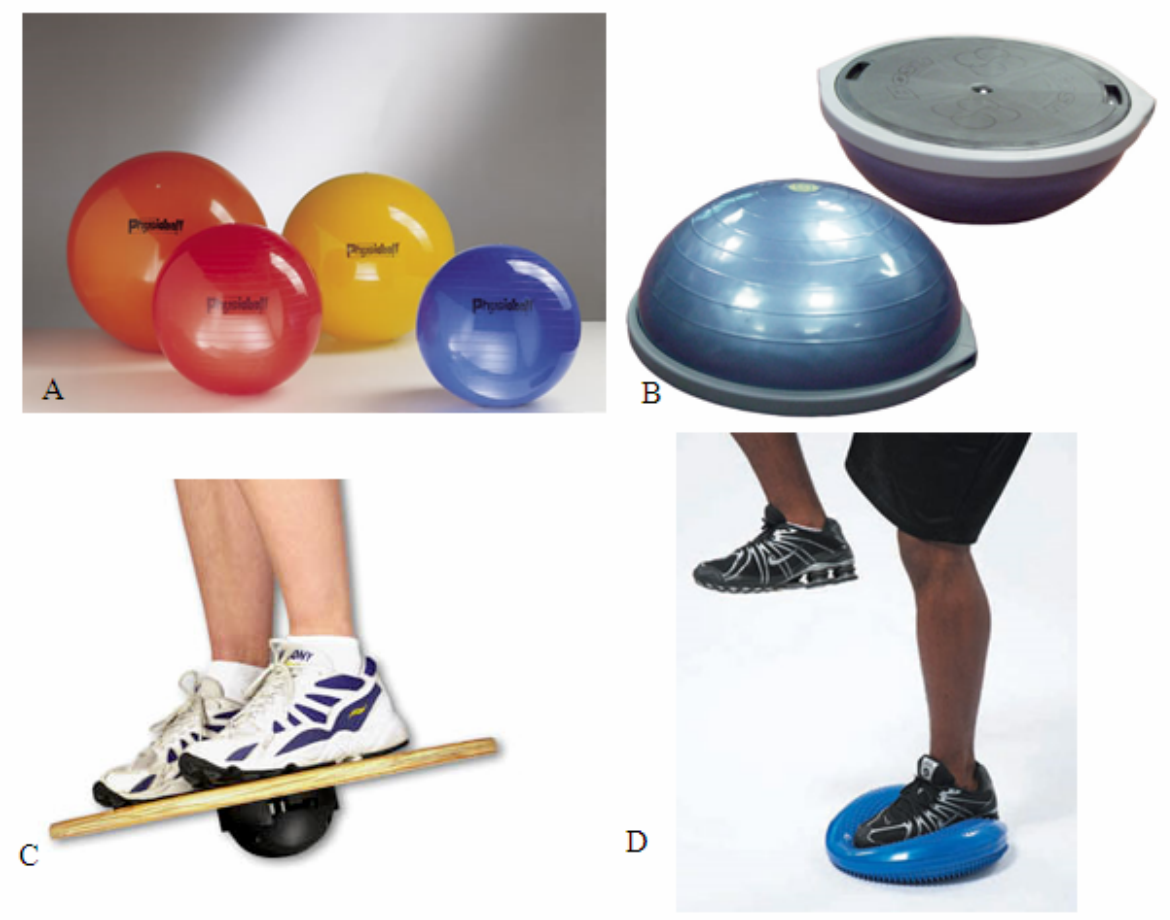

Figure 4: Instability Devices on the Market

Figure 4A [1], Figure 4B [6], Figure 4C [8], Figure 4D [9].

Some of the more popular instability devices that are on the market today are the Swiss or Physioball (Figure 4A), the Hemispherical Phyioball (Figure 4B), inflatable disks (Figure 4D), wobble or balance boards (Figure 4C), foam tubes, and 
high and low density foam platforms. These devices engage both the proprioceptive sense as well as the vestibular sense.

The Physioball is an air pressured ball that can be purchased in a variety of diameters depending on the use. These balls have been used by physical therapists since before World War II [11]. These balls can be used for various activities from pushups to abdominal crunches. The way the physicoball works is by providing an unstable platform under the subject. When the subject then goes to perform an exercise, they must engage more muscles to stabilize their body to prevent them from tipping over. This leads to a higher muscle activation overall.

The hemispherical physioball has one side that is an inflated dome with the other side being made of a flat hard rubber. These boards have been gaining popularity since the 1980s [11]. This device has a hard plastic flat surface on one side with an inflatable dome on the other side. It can be used with either side facing up depending on the exercise chosen. This device engages the core abdominal muscles, the back muscles, as well as smaller stabilizer muscles because the user is having to constantly be engaged to keep the board stable [12].

Wobble boards are what many people think of when a balance board is mentioned. They come in a variety of shapes and sizes depending on what the user wants to do. Exercises can be done while standing on the board or the board can be used for other exercises such as pushups.

The inflatable disks can also be used for a multitude of things. They can be used much like a wobble board with the user standing on the board, or the user has the option to sit while performing the exercises. 
The use of unstable boards is used on the premise that the more unstable a surface is, the more it will stress the neuromuscular system compared to the same exercise on stable ground [11].

\section{Effects of Balance Board Training}

It has been shown in previous studies that performing an exercise on an unstable surface causes an increase in core muscle activation to maintain control during the performance of the given exercise. It is thought that this increase in muscle activation is to increase the spinal stability as well as whole body stability in order to prevent the body from falling off of the unstable surface [13]. If there is a higher degree of instability, it can result in anywhere from $20-30 \%$ greater activation of the spinal stabilizing muscles [11]. While the use of such devices may lead to a less intense limb exercise, they still provide high core muscle activation. Other studies have been done that have shown that while unstable surfaces can increase muscle activation, it varies depending on the level of physical activity the subject usually participates in. People who are more active will not get as much challenge or muscle activation from the unstable surfaces as those who are inactive. This is most likely do to the fact that the more active individuals muscles are more highly trained already so the small instability of the balance board will not result in a large enough change in their stabilizer muscles to make a difference. People who are less trained will have weaker muscles and therefore need to activate more muscles to remain stable. If a sedentary individual were to participate in prolonged balance board training they will be able to improve their spinal stability. This is because they will be 
starting at a level of weaker stabilizer muscles and will build them up over the course of their training [11].

\section{Studies on Balance Boards}

Balance boards have been used in many studies in an attempt to understand their full impact on the human body. Many different types of balance board have been tested using a variety of participants with varying levels of activity. It is through these studies that a better understanding is gained of how balancing affects the body. A detailed description of the core muscle anatomy will be discussed later.

\section{Studies on Core muscles}

There have been various studies done on the effects of balance board training on the core muscles with groups ranging from untrained subjects to active golfers. In a study done by Vera-Garcia et al., the effect of varying degrees of a liable surface were observed on the abdominal wall. The group studied both the amount of muscle activity as well as the coactivation between the rectus abdominis and obliques on the varying surfaces. Eight subjects in total were used and asked to perform four different curl up exercises: one on a stable platform and three on varying levels of unstable platforms. EMG signals were recorded from four different locations on the abdominal muscles and normalized against the maximum contractile force. They found that by performing the exercises on unstable surfaces there was a large increase in the muscle activity, with a larger gain seen in the obliques compared to the rectus abdominis. The group concluded that not only did the unstable platform have an 
effect on the amount of muscle activate it also had an effect on the coactivation between the two muscles that were studied [13].

In another study the focus was to compare the effects of using the physioball during core stability and balance exercises over a period of five weeks. The study consisted of 30 subjects, 15 in the control group and 15 in the experimental group. Both groups performed curl ups and back extensions, the experimental group on the physioball and the control group on the floor. They collected EMG data of the rectus abdominis, and erector spinae muscles, took measurements using the Cybex Norm System of the abdominal, back and knee strength, and had the participants perform 2 unilateral stance balance tests. This study found that the experimental group had a greater mean change in EMG during flexion and extension activity as well as greater balance scores compared to the control group [14].

A study done by Thompson et al. examined the effects a functional training program have on improving sports performances or a subjects functional fitness. The group chose to focus on golfers to see if they could improve the club head speed and the functional fitness of elderly men. The study consisted of 18 subjects, 11 experimental and 7 control subjects. The experimental group participated in a variety of exercises including flexibility, core stability, balance, and resistance exercises over the course of 8 weeks. The control group had no change in their regular routine. The groups were measured on their club head speed and the Fullerton Senior Fitness Test measurement. The found that the club head speed greatly increased as well as several of the components of the fitness test [15]. 
Other studies have been done to determine the effects of unstable surface training on healthy, trained subjects. In a study done by Cressey et al., the study lasted ten weeks and had 19 participants who were deemed healthy trained members of a collegiate men's soccer team. Ten subjects were in the experimental group with nine in the control. The experimental group performed lower body exercises on an inflatable disk why the control group performed the same exercises on stable surfaces. It was found that there was no great improvement of the unstable group over the stable group for the trained individuals for the healthy, trained athletes [16]. This is what would have been expected however because the subjects would already have very well trained stability muscles so increasing the use of them would not have a significant impact.

Studies have been done to determine the effect that balance training has on specific functional tasks. A study done by Yaggie et al. studied 36 subjects, 19 control and 17 experimental. The experimental group performed various core training exercises using a balance training device while the control group did not change their routine. The subjects performed a series of postural limits and functional tasks. The researchers found that the balance training improved the performance of some sport related activities and posture control, however they were not able to say if they felt the training would be good for general functional improvement [17].

For most cases these experiments have shown that by performing exercises on the unstable surfaces, there will be an increase in performance in some way. This is due in part because the stabilizer muscles are being more engaged while on the unstable surfaces creating a stronger core. The experiment with the trained soccer 
players however, showed that when the subjects are already well trained, there might be little to no improvement seen by performing the exercises on an unstable platform. This means that the amount of activity that the subjects encounter must be taken into account when looking at the improvement seen during balance exercises.

\section{Studies on The Ankle}

The core musculature is not the only area being researched for the effects of balance training. Many studies using unstable platforms have been done on the ankle joint. Ankle sprains are one of the most common injuries in the athletic population studies show they occur in 80 percent of athletic individuals. Of these 80 percent there is about a 73 percent recurrence in the injury [18].

In a study done by Clark et al., they investigated the effects a wobble board training would have on the onset of muscle activity and perception of stability in people with functionally unstable ankles. The researchers used nineteen male participants who had encountered at least three sprained ankles in the last two years, but had been injury free for at least three months. Using surface EMG the users participated in either the control group where subjects did their normal routine or the experimental group where subjects were monitored for four weeks in a wobble board program. The researchers found that the wobble board showed a significant improvement in the perception of the subject's functional stability and reduced the participant's chance of further sprains. This was due in part to the decreased time to activation of the muscles around the ankle. By the ankle surrounding the muscle being able to react faster to sudden changes in stability, it decreases the chance that the ankle will twist because there will be more support faster [18]. 


\section{Canadian Society for Exercise Physiology}

The Canadian Society for Exercise Physiology took a position on the use of instability to train the core in athletic and nonathletic conditions. They felt that specific training practices aimed at targeting the core muscles was important to look at when dealing with activities of daily living, sports, and rehabilitation. From reviewing a variety of articles similar to the ones discussed previously, they noted that performing exercises on unstable surfaces causes a greater increase in the core muscle activation compared to a stable surface. From the different research that has been done, the society has made recommendations for athletes, rehabilitation, and the general public based on the activity level and the benefits that these groups will gain from this type of exercise [19].

For athletes who are working for maximal strength, power, and velocity, they should not limit their training program to exercises performed on unstable ground. They should however, emphasize more high intensity ground based lifts. Having good spinal stability is essential for many sports skills so they should not focus on just unstable platforms, they should work on having a well rounded routine which could include resistance training with an unstable component added in. This unstable component could involve a balance board of some type or by using free weights. The unstable training should not be used if the subjects are looking for absolute strength or power because with the unstable training these are impaired and may be insufficient to create enough stimulation [19]. This recommendation is understandable based on the previous studies mentioned in this paper because the 
subjects will already have their stabilizer muscles built up, so performing exercises only on a balance board will not have a large effect on their training.

For people who are working on rehabilitation it has been shown that the unstable devices have been effective in decreasing lower back pain and increasing the sensory efficiency of the soft tissue thats job is to stabilize the knee and ankle joints. The Society feels that working with unstable surfaces can provide some protection from injury and even improve recovery from an injury to the core or anywhere else [19]. This recommendation takes into effect studies such as the one done by Clark et. al which explained that by training on a balance board, the muscles can be trained to respond faster when there is a change in stability. This would mean training on a balance board would be good for preventative measures as well as rehabilitation because the muscles can be trained to respond faster which will decrease the chance that the joint will move in the wrong direction again.

As for the general public the Society recommends that ground based free weight lifts should be used as the foundation for training the core musculature. The use of instability devices can still have a positive effect on the subject and has good health benefits, however maximal strength or power development can be compromised with this type of training. People who are working for health related fitness, who cannot access, or are not interested in ground based free weight lifting can achieve functional health benefits from instability training [19].

The Society's final thought is that during times when the subject is using lower loads the unstable training devices and exercises can stimulate high muscle activation which can be very beneficial [19]. This being said, the group of interest for 
this study is users who are in wheelchairs meaning that they will be either working on rehabilitation or will have a smaller access to ground based free weight lifting. It can be hypothesized from the information presented by the Canadian Society for Exercise Physiology that by using an unstable platform to perform the recommended exercises will produce a higher muscle activation and provide greater health benefits for the subjects.

\section{Electromyography}

Electromyography (EMG) is the recording of electrical activity produced by the muscles of the body. In order to understand how the signal is collected it is important to first understand how the signal is produced.

\section{Skeletal Muscle Anatomy}

Skeletal muscle (Figure 5) is a contractile tissue made up of fibers that run parallel to the muscle, also known as fascicles. These fibers are made up of myofibrils and the myofibrils are made up of actin and myosin which are responsible for the actual contraction of the muscle. The skeletal muscle is controlled by the nervous system. Nerves run from the brain down to the different fascicles. Where they meet is called the neuromuscular junction. It is through this junction that the muscle receives its signal to contract from the nerve [20].

\section{Muscle Contraction}

A muscle contracts through a series of 4 different phases. These phases include excitation, excitation contraction coupling, contraction, and relaxation. 
The excitation phase is when an action potential in a nerve fiber leads to an action potential in the muscle fiber. This happens when a nerve fibers enters the synaptic knob and the calcium outside the neuron enters the synaptic knob. The calcium causes a release of acetylcholine into the synaptic clef which binds to receptor proteins in the sarcolemma. This causes sodium to diffuse into the cell and potassium to flow out. This leads to an end plate potential which causes the ion gates on the sarcolemma to open which causes an action potential. This leads to the muscle being excited [20].

During the excitation contraction coupling the excitation reaches the $\mathrm{t}-$ tubules in the muscle and continues through them to the sarcoplamsa. The ion gates open and the calcium diffuses out of the sarcoplasmic reticulum and into the cytosol. The calcium binds to tropomin in the thin filaments causing the active sites to become exposed to myosin heads on the active filaments [20].

The next step is the contraction phase. During this the muscle fiber develops tension and may shorten. The myosin head has ATP bound to it which hydroloizes and cause the myosin hea to extend into the high energy position. At this position it binds to the thin filament and then releases ADP. This release causes the myosin to pull the action with it as it returns to its original position. The myosin will attach to a new ATP and repeat the process [20].

The final step of the muscle contraction is for the muscle to return to its resting length. This happens when the nerve signals stop arriving so the acetylcholine is not received. This leads to no more stimulation of the muscle so the calcium is 
pumped back into the cisternae. The calcium dissociates from the troponin and the tropomyosin move back into position to block the active site [20].

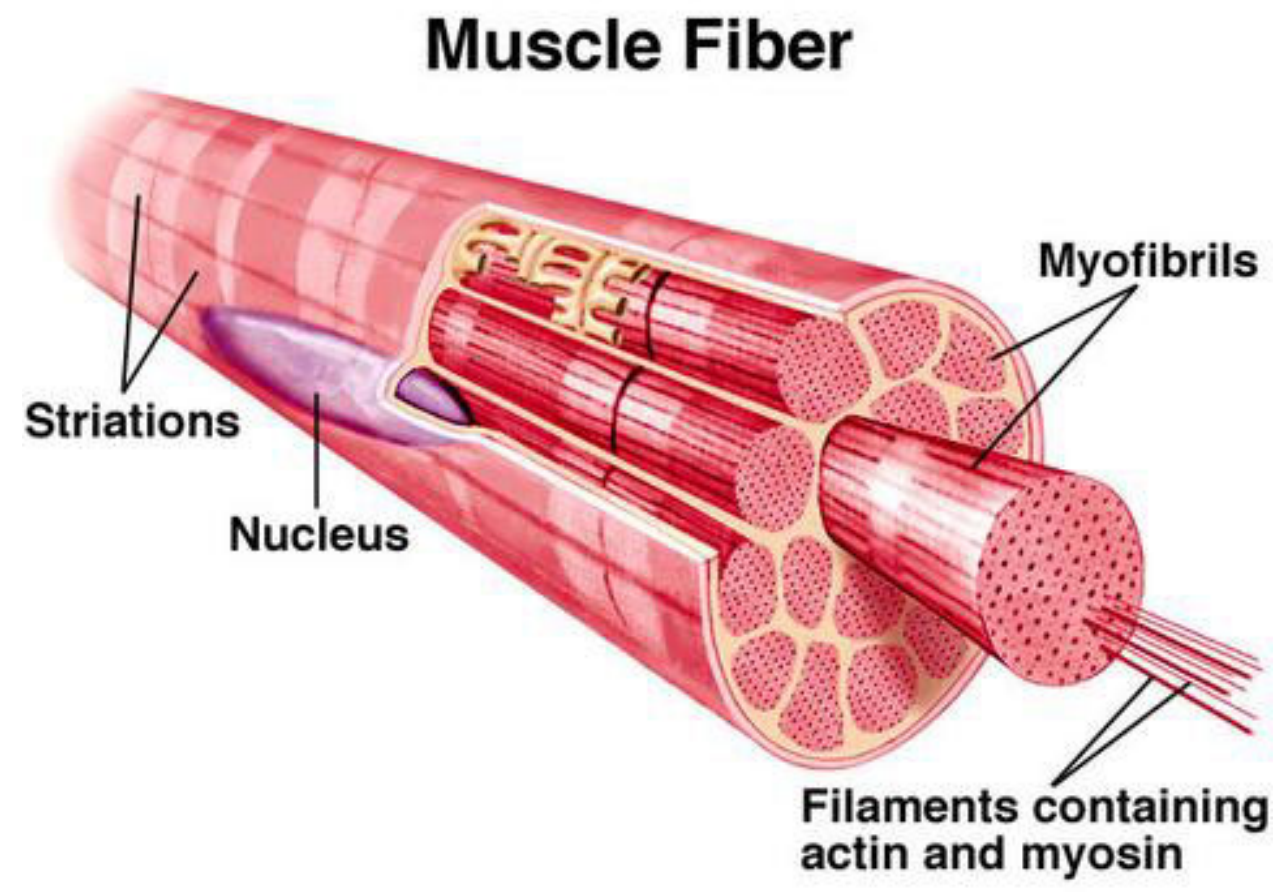

Figure 5: Muscle Fiber [3]

\section{Collection of EMG Signal}

The signal that is collected by the EMG is from the change in the membrane potential that is traveling through the muscle. By placing electrodes over the muscle of interest we can collect this signal that is produced. The raw EMG signal shows the electrical activity of the muscle at a given point in time. As the strength of the muscle contraction increases, the density of the action potentials increases and the raw EMG signal can represent the electrical activity of thousands of individual muscle fibers [21]. 


\section{Processing EMG Data}

There are many ways to process the raw EMG signal from voluntary contractions. The way that the data is processed greatly depends on knowledge the researcher would like to gain from the data. One way of processing the data is to take the root mean square of the data, as shown in Figure 6. This is done by inverting the negative portions of the EMG by squaring the whole signal. The whole signal is then averaged and then the square root is calculated. By doing this, the individual spikes are smoothed out and the course of changing activity is much clearer [21].

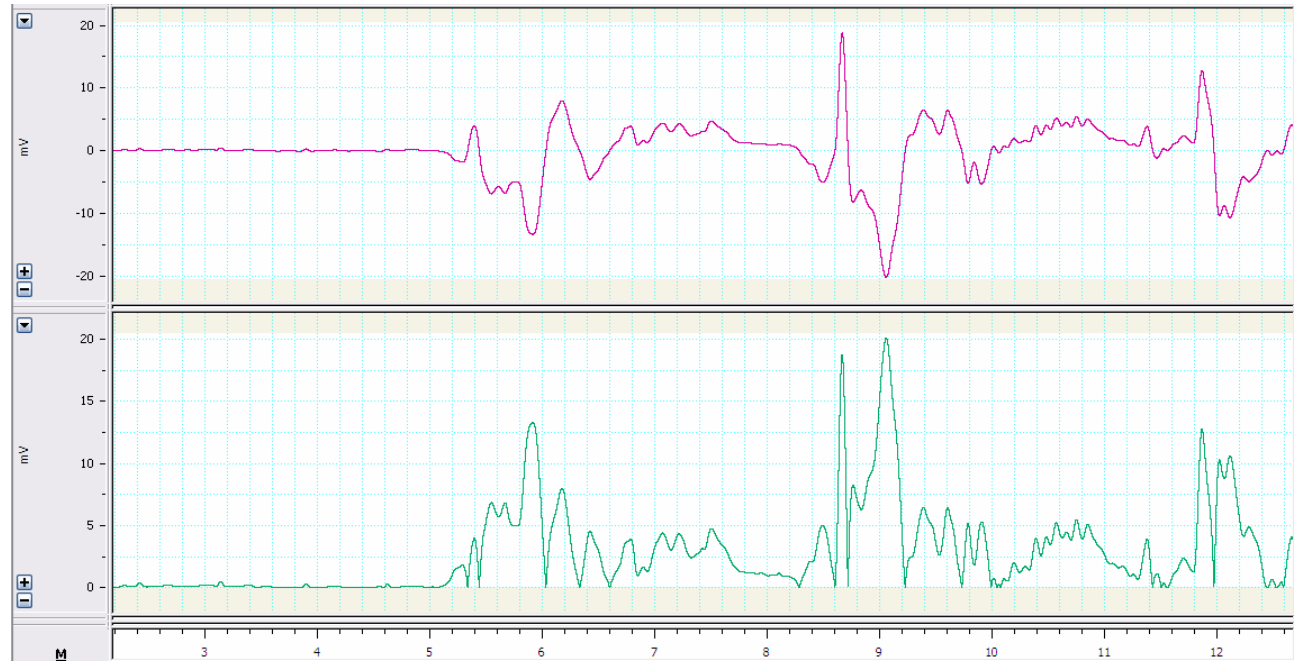

\section{Figure 6: EMG Signal Converted to RMS}

Another way to analyze the EMG data is to take the integral of the area under the curve. This will result in a way to determine how much muscle activity is required to perform a certain job. To do this the raw EMG signal can be rectified, where the absoloute value of the signal is taken. This can then be passed through a low pass filter to remove the noise seen in the signal. This signal can then be integrated to find the overall muscle effort required [22]. 
There are also various software packages on the market to be used for EMG analysis. These packages allow for a variety of analysis to be done on the signal. One package is made by Motion Lab Systems and allows the user to analyze the signal using Fast Fourier Transform techniques along with more traditional EMG analysis methods [23]. Another software pack made by BIOOAC Systems Inc allows the user to derive averaged rectified EMG, derive integrated EMG, derive RMS, perform EMG frequency and power analysis, along with location muscle activation [24]. These software packs allow the user to perform a multitude of tests very quickly which aids in a faster data analysis.

\section{Abdominal Muscles}

The abdominal muscles are what the body uses to control posture and keep the body staying upright. The muscles that run down the back work with the abdominal muscles to keep the body stable and counteract each other in order to provide fine tuned muscle movement. During balance exercises, these muscles become highly activated in order to keep the person stable and to prevent them from falling over.

\section{Functional Anatomy}

The erector spinae group of muscles works closely with the abdominal muscles and works to straighten the spine into extension and keep it erect. The erector spinae group is made up of three muscles, the spinalis, the longissimus, and the ilocostalis which all run along the spine. Conversely, the rectus abdominis helps to flex the spine. The erector spinae muscles work to slow down forward flexion of the spine when bending forward while the rectus abdominis slows down trunk extension. The abdominals function as a counterpart to the erector spinae group 
because they lengthen under load to make sure that the spine does not extend to far backward as the torso is pulled upright. As long as these two sets of muscles are healthy they will work together to prevent the spine from arching or rounding too far or too quickly. By doing this they are able to minimize the stress to the spine and torso [25].

\section{Rectus Abdominis}

The rectus abdominis (RA) is a paired muscle that runs vertically on either side of the anterior wall of the abdomen (Figure 7). The muscle inserts on the costal cartaliges of ribs 5, 6, 7 and the xiphoid process, as well as to the crest of the pubis and pubic tubercle and the front of the pubis symphysis inferiorly [26]. It is believed that this muscle contracts together and that there is no difference in the contractile force located at one end compared to the other. The role of the RA is to aid in the movement and stabilization of the lumbar spine. It does this because it is able to produce and control movements of the spine relative to the pelvis and the pelvis relative to the spine [26]. 

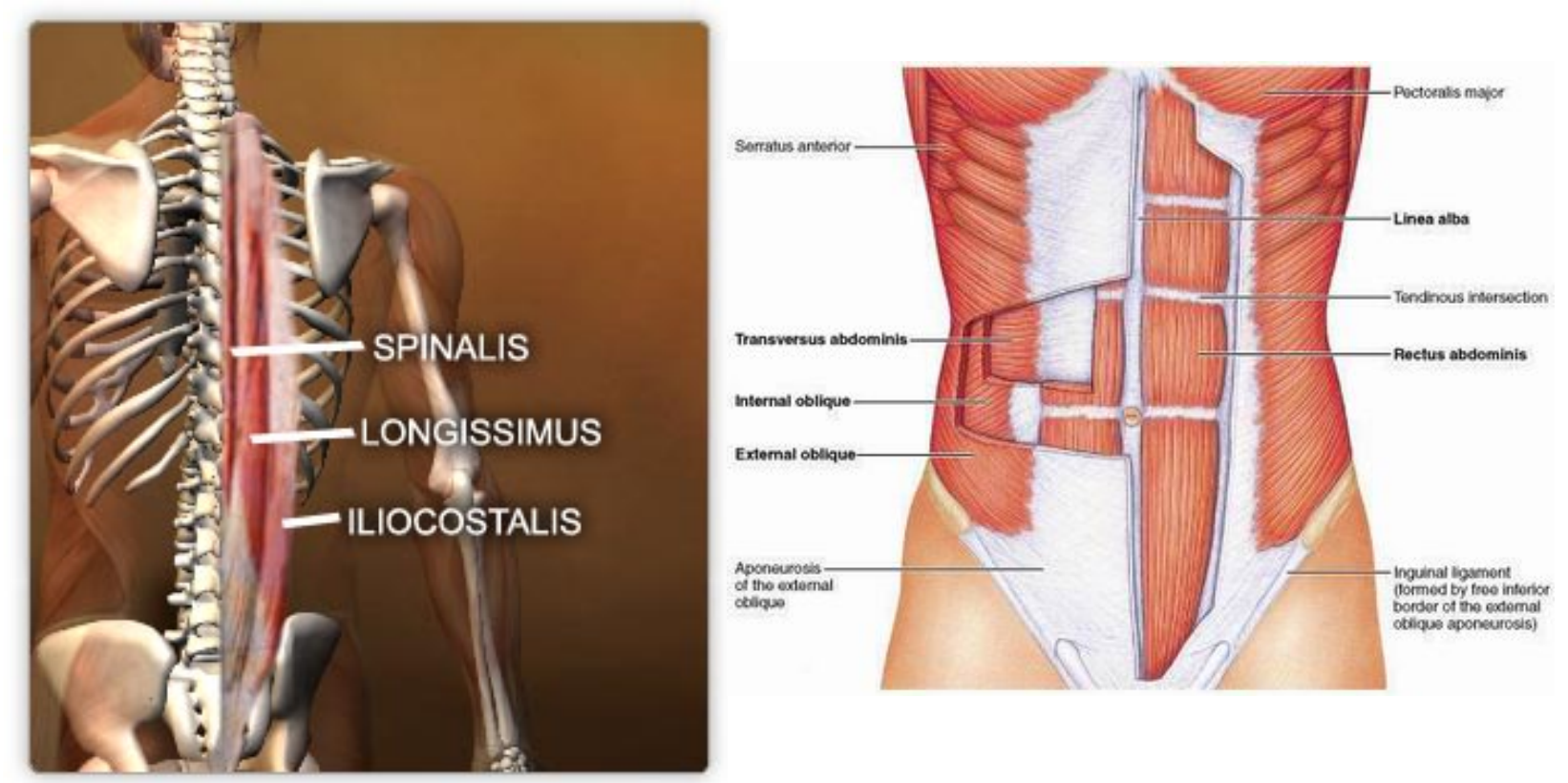

Figure 7: Erector Spinae Group and Abdominal Muscle Anatomy [4], [7]

\section{External Obliques}

There are three groups of muscles that make up the obliques, the internal obliques, the transverse obliques, and the external obliques. The external obliques are the outermost of the three and are what will be focused on in this study because they are the most accessible with surface electrodes. In order for a surface electrode to detect a signal from a muscle, the muscle must be close to the skin, otherwise the signal will be lost. These oblique muscles are on the lateral anterior aspect of the trunk as you can see in Figure 7. These muscles function to pull the chest down and compress the abdominal cavity to play an important role in respiration. They also have a small impact on the flexion and rotation of the vertebral column. 


\section{Abdominal Muscle Exercises}

There are many different types of abdominal muscle exercises that can work on different areas of the trunk. The most common of these exercises require the individual to be lying down on a flat surface to perform the exercise. There are, however, variations of the exercises that include seated exercises as well as things such as left lifts while supporting the upper body by the subjects arms between two bars. While seated exercises can work the same muscles, they do not activate them to the same degree as when the subject is doing the exercise on the ground. For example for the rectus abdominis muscle to be highly activated the subject needs to be at an angle greater than ninety degrees so that the muscle is working against gravity. When a user is seated they are usually sitting at a ninety degree angle so it is difficult to activate this muscle.

The following abdominal exercises can be prescribed to patients for as a rehabilitation method for lower back injury or as a component for various fitness training programs [27]. These exercises work different muscles in the core including the rectus abdominis and the abdominal obliques.

\section{Floor Exercises}

This study will use three different traditional abdominal exercises with the subject lying on the ground. These include the abdominal crunch, the reverse crunch, and the full vertical crunch (Figure 8).

The abdominal crunch consists of the individual lying on their back with their knees bent approximately 90 degrees. The subject's hands are placed on either side of the head while he/she contracts the abdominals and flatten his/her lower back against 
the floor. Using his/her abdominal muscles, the subject will then proceed to lift the shoulder blades one or two inches off of the floor. While lifting it is important to make sure that the individual exhales and keeps his/her neck straight with the chin up. This position will be held for a couple of seconds before the subject can slowly lower their upper body while keeping the abdominal muscles contracted. This exercise is good to work out the rectus abdominis muscle [28].

A
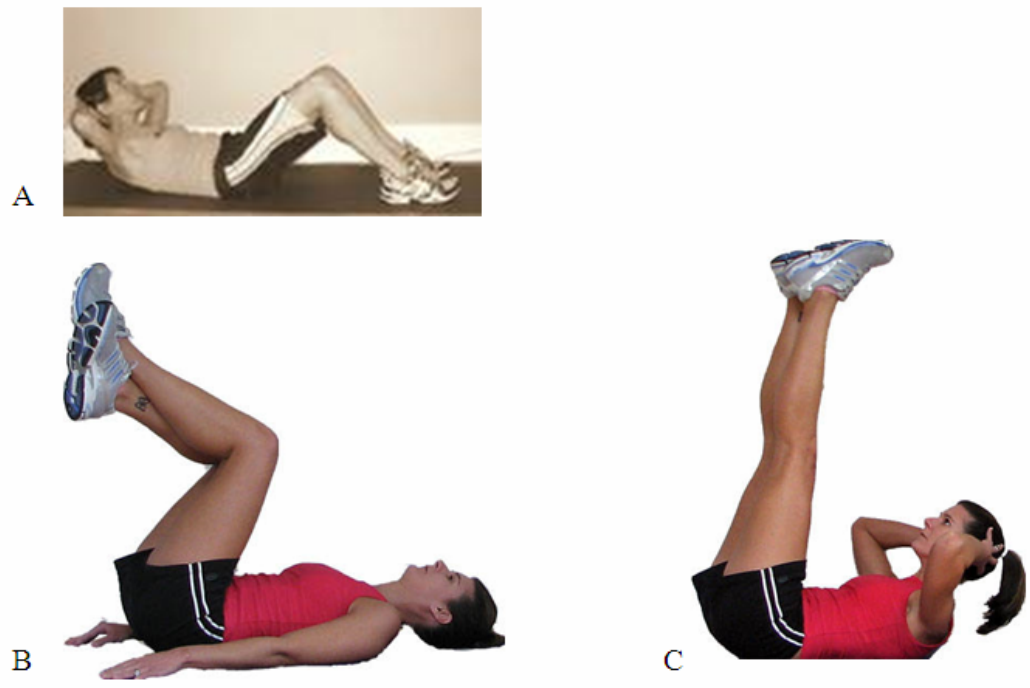

\section{Figure 8: Floor Abdominal Exercises}

Figure A [28] Figure B and C [29].

The reverse crunch starts out with the individual lying on his/her back on the floor. The subject's hands can be either placed on the floor by the sides or behind the head. The knees are then brought in towards the chest until they are bent to 90 degrees with the feet either together or crossed. The individual will then contract the abdominal muscles to curl his/her hips off of the floor and to reach his/her legs towards the ceiling. The subject's legs can then be lowered back to the starting 
position. This exercise works the rectus abdominis, and while the lower abdomen will feel like it is getting most of the work the entire muscle is working [29].

The last floor exercise is the full vertical crunch. This exercise also begins with the individual lying flat on his/her back. The subject's legs are then extended up towards the ceiling. With the subject's hands behind his/her head they will contract the abdominal muscles to lift his/her shoulder blades off of the floor. While doing this the subject will press the heels of his/her feet towards the ceiling which will create a "U" shape with the torso. The shoulders and legs can then be lowered and returned to the starting position. This exercise works the abdominal muscles by causing both the upper and lower body to engage in the exercise at hand [29].

\section{Seated Exercises}

Seated exercises can be helpful for many individuals, not only users of wheelchairs. These can be beneficial to people who are pregnant, have difficulties standing, or even people who are just starting to work on their core musculature. The three seated exercises that will be used in this study are the torso twist, the seated crunch, and the sitting abdominal bend down which can be seen in Figure 9.

The torso twist is a very basic seated exercise. The individual starts by sitting in the chair with his/her hips, knees and torso facing forward. The exercise begins with the individual rotating his/her torso to the right as far as they comfortably can while keeping the hips and knees facing forward. The subject should be focusing on squeezing the muscles that are around his/her waist. The individual will then rotate back to center keeping the motion slow and controlled. This movement is then repeated on the left side. This exercise is used for targeting the obliques [2]. 
The next exercise that will be investigated is the seated crunch. During this exercise the individual will sit in a chair with his/her back off of the backrest. The subject will be asked to sit up straight and look straight ahead making sure that his/her chin is level. Both hands will be placed on the subject's knees as they draw in the abdominal muscles. The subject's shoulders will then crunch down as he/she bends at the ribs and exhale. As the subject does this it is important to make sure that his/her chin is lifted away from their chest as they crunch. They can then return to a seated position. This exercise is used to work the rectus abdominis muscle [30]. 

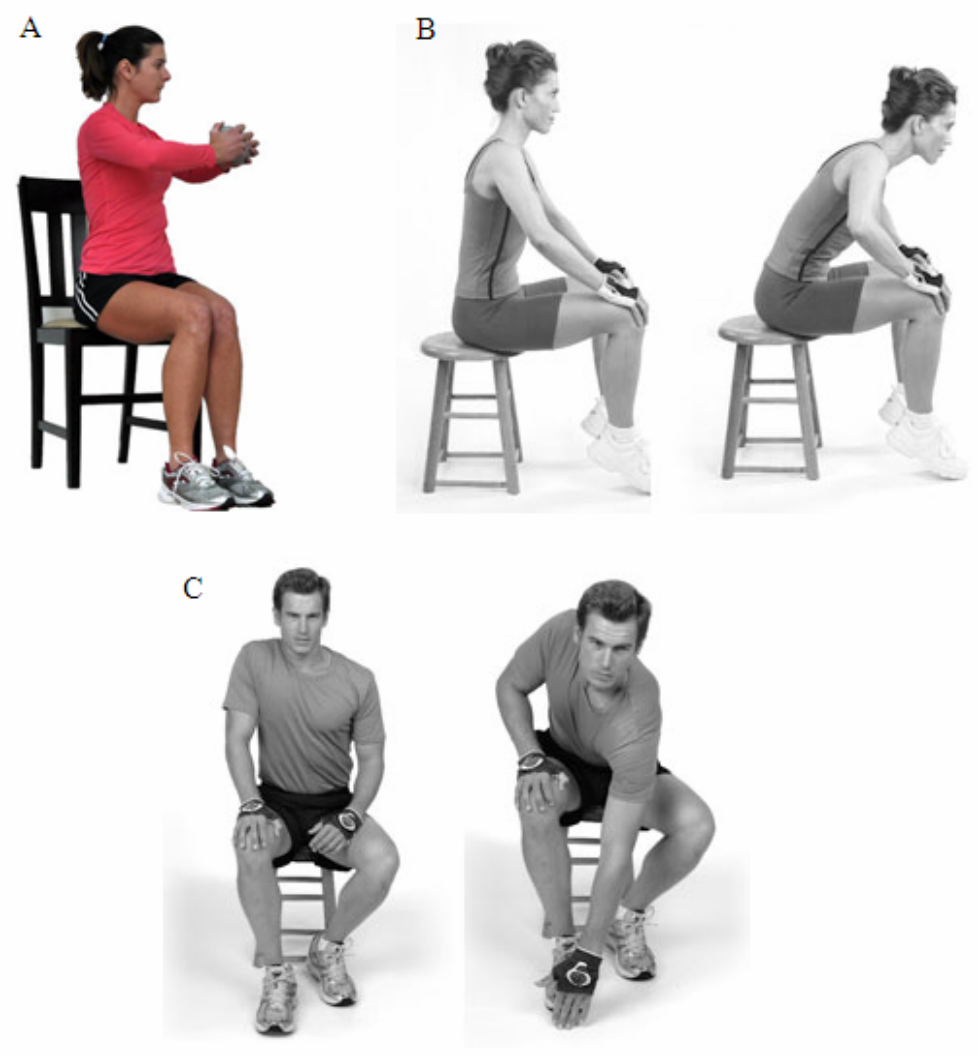

\section{Figure 9: Seated Abdominal Exercises}

Figure A [2] Figure B and C [5].

The last seated exercise is the seated abdominal bend down. During this exercise the individual will alternate sides starting with one hand placed on the knee. At the start of the exercise the subject will place a downward force onto this knee while he/she contracts in the abdominal muscles. Using the opposite hand the subject will then reach across his/her body to touch the foot. While keeping pressure on the knee the subject can then return to the initial seated position. Every rep of this should take around two to five seconds. This exercise should work a mixture of both the abdominal obliques as well as the rectus abdominis [5]. 
In conclusion, when an unstable platform is added to any exercise routine it can provide a variety of health benefits. The balance platforms lead to an increase in muscle activation and with continued training these muscles can be strengthened. By strengthening these muscles the subject can improve their overall health as well as decrease their chance for muscle injury. This study will examine if using a wheelchair balance board can cause an increase in core muscle activity in a subject. 


\section{Chapter 3: Methods}

From the background research is it clear that balance boards can have a variety of benefits for various users. This study aims to determine if there are any benefits for a user in a wheelchair to use the wheelchair balance board. The methods focus on the abdominal muscles to determine if there is an increase in abdominal muscle activity while performing various exercise on the wheelchair balance board as opposed to a stable surface.

All procedures were approved by the Human Subjects Committee at California Polytechnic State University San Luis Obispo. A detailed protocol consisting of step - by - step directions of what would be going on during the study as well as copies of the informed consent, pre study questionnaire and Par - q survey were submitted to the Human Subjects Committee. An analysis of all risks associated with the study was also included. After approval was granted the study was started.

\section{Procedure}

Ten able - bodied individuals who were students at California Polytechnic State University San Luis Obispo participated in this study. Upon arrival to the testing room, the subjects were asked to fill out an informed consent form, a pre study questionnaire, and a Par-q survey all which can be found in Appendix A. The informed consent form explained the purpose of the study, what the subjects were being asked to take a part in, his/her expected time commitment, as well as any risks the subject may be exposed to and who to contact if he/she should have any problems. The risks for this experiment were very minimal: there was a slight chance of skin 
irritation, rash, or a muscle strain. To help minimize these risks the pre - study questionnaire was given.

The pre study questionnaire consisted of five questions and was given to the subjects prior to their participation in the experiment. The subjects were asked to fill out the information to the best of their knowledge. The first two questions gathered information about the age and sex of the subject. This data was used to make sure that the subject fell into the approved age range of the study and to make sure that the subjects gathered were half male and half female. The next question asked about the subject's current activity level. This was of importance because as seen in the background research, people who are more active will receive less benefit of using a balance board as compared to those who are less active. The fourth question asked about any injuries within the last six months. The main injuries that were of concern were any to the core muscles that were being examined or to the back muscles. If the subject had had an injury to this area and had been recovering there could be the chance that they could injure themselves again during the study, or the data collected from then could be not a true representation of their abilities. After an injury doctors usually ask patients to take it easy during the recovery process which can lead to a loss in muscle strength. The final question of the survey was to find out if the subjects were allergic to any surface adhesives. The electrodes contained surface adhesive to attach them to the skin so it was important to know if the subject was allergic so that they would not end up with a rash or other possibly more severe complications. All subjects completed the survey with no concerning answers. 
The Par-Q survey is used by Health Canada to determine if people ages 15-69 are eligible to become more physically active. It is usually safe for more people to become more active, however this is a survey that can be taken to make sure that the chances of an adverse event will be small. The survey consists of seven questions of which the subject must answer "no" to all in order to participate in this study. If a subject answered "yes" to any of the questions they were asked not to participate in the study. The questions covered include things such as if the subject has ever had a heart condition where the doctor said they should be consulted prior to starting a new exercise program, if they feel pain in their chest during physical activity, if they have had chest pain in the last month, if they lose their balance due to dizziness or ever lose consciousness, if they have bone or joint problems, if they are currently on certain prescription drugs or if they have any other reason that they should not perform any physical activity [31]. All ten subjects answered "no" to all seven questions and were allowed to participate.

\section{Participant Information}

Ten subjects participated in this study - five male and five female. Their ages ranged from 19 to 23 years old with an average age of 21.7 years old. Table 1 shows the detailed data collected from the pre study questionnaire about each individual subject. It includes all the data about the subject's age, sex, current activity level, injuries within the past six months, and if they are allergic to surface adhesives. As seen in Table 1, the ten subjects had a wide variety of current physical activity ranging from exercising multiple times a week to none at all. Six of the subjects exercised multiple times a week, two exercised once a week, one exercised rarely, 
and one exercised none at all. Only two of the subjects had had injuries within the past six months, but both were cleared by a doctor or trainer to continue working out or told that they had healed. Subject six had a muscle strain to his right intercostals muscle which had healed by the time of the experiment. Subject seven had multiple lower limb injuries including a strained quadriceps, a pulled hamstring, and a sprained ankle. He had also been cleared by a doctor to continue his training and exercise. These injuries were all lower limb so it could be assumed that they would not be affected by the tests being run because the muscles being activated are in the core of the body. No subjects had any known allergies to surface adhesives.

Table 1: Subject Information

\begin{tabular}{|c|c|c|c|c|c|}
\hline & Age & Sex & $\begin{array}{c}\text { Current Activity } \\
\text { Level }\end{array}$ & $\begin{array}{c}\text { Injuries in Past } \\
6 \\
\text { Months? }\end{array}$ & $\begin{array}{l}\text { Allergies to } \\
\text { Surface } \\
\text { Adhesives? }\end{array}$ \\
\hline $\begin{array}{c}\text { Subject } \\
1\end{array}$ & 22 & Female & $\begin{array}{l}\text { Multiple times a } \\
\text { week }\end{array}$ & No & No \\
\hline $\begin{array}{c}\text { Subject } \\
2\end{array}$ & 22 & Female & Once a week & No & No \\
\hline $\begin{array}{c}\text { Subject } \\
\mathbf{3}\end{array}$ & 22 & Male & $\begin{array}{l}\text { Multiple times a } \\
\text { week }\end{array}$ & No & No \\
\hline $\begin{array}{c}\text { Subject } \\
4\end{array}$ & 20 & Female & $\begin{array}{l}\text { Multiple times a } \\
\text { week }\end{array}$ & No & No \\
\hline $\begin{array}{c}\text { Subject } \\
5\end{array}$ & 23 & Male & Once a week & No & No \\
\hline $\begin{array}{l}\text { Subject } \\
6\end{array}$ & 19 & Male & $\begin{array}{l}\text { Multiple times a } \\
\text { week }\end{array}$ & Yes & No \\
\hline $\begin{array}{c}\text { Subject } \\
7\end{array}$ & 22 & Male & $\begin{array}{l}\text { Multiple times a } \\
\text { week }\end{array}$ & Yes & No \\
\hline $\begin{array}{c}\text { Subject } \\
8\end{array}$ & 23 & Male & $\begin{array}{l}\text { Multiple times a } \\
\text { week }\end{array}$ & No & No \\
\hline $\begin{array}{l}\text { Subject } \\
9\end{array}$ & 22 & Female & Rarely & No & No \\
\hline $\begin{array}{c}\text { Subject } \\
10\end{array}$ & 22 & Female & None & No & No \\
\hline
\end{tabular}




\section{Electrode Placement}

Ten electrodes in total were used on each subject. The area was prepped using alcohol swabs to remove any dead skin and to ensure good contact, and Kendall surface electrodes (Figure 10) were used (part number 31.1245.21). A Product Data Sheet can be found in Appendix B. These are disposable electrodes that are pre - gelled to allow for easy application. They are made of latex free foam, which was beneficial due to the low possibility of allergic reactions. They are one inch electrodes with a snap on connector on the back that made connection to the PowerLab easy [32].

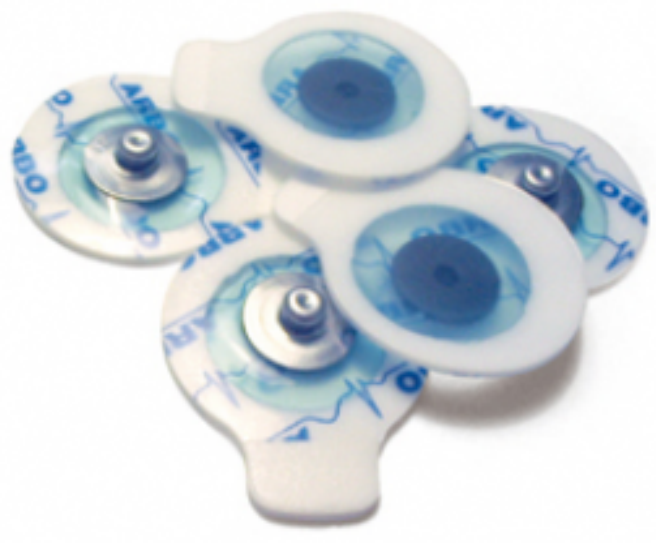

\section{Figure 10: Kendall Surface Electrodes [32]}

The electrodes were placed after the areas had been cleaned. Two electrodes were placed over the subject's clavicle on either the left or right side for the ground. Four electrodes were placed over the obliques with two on each side. The location for these were found by locating the top of the iliac crest on the subject and then placing the electrode above that in line with the umbilicus. The last four electrodes were 
placed over the rectus abdominis. The location of these electrodes was approximately $3 \mathrm{~cm}$ on either side of the umbilicus and $5 \mathrm{~cm}$ superior and inferior to the umbilicus [33]. A picture of the electrode placement setup can be seen in Figure 11.

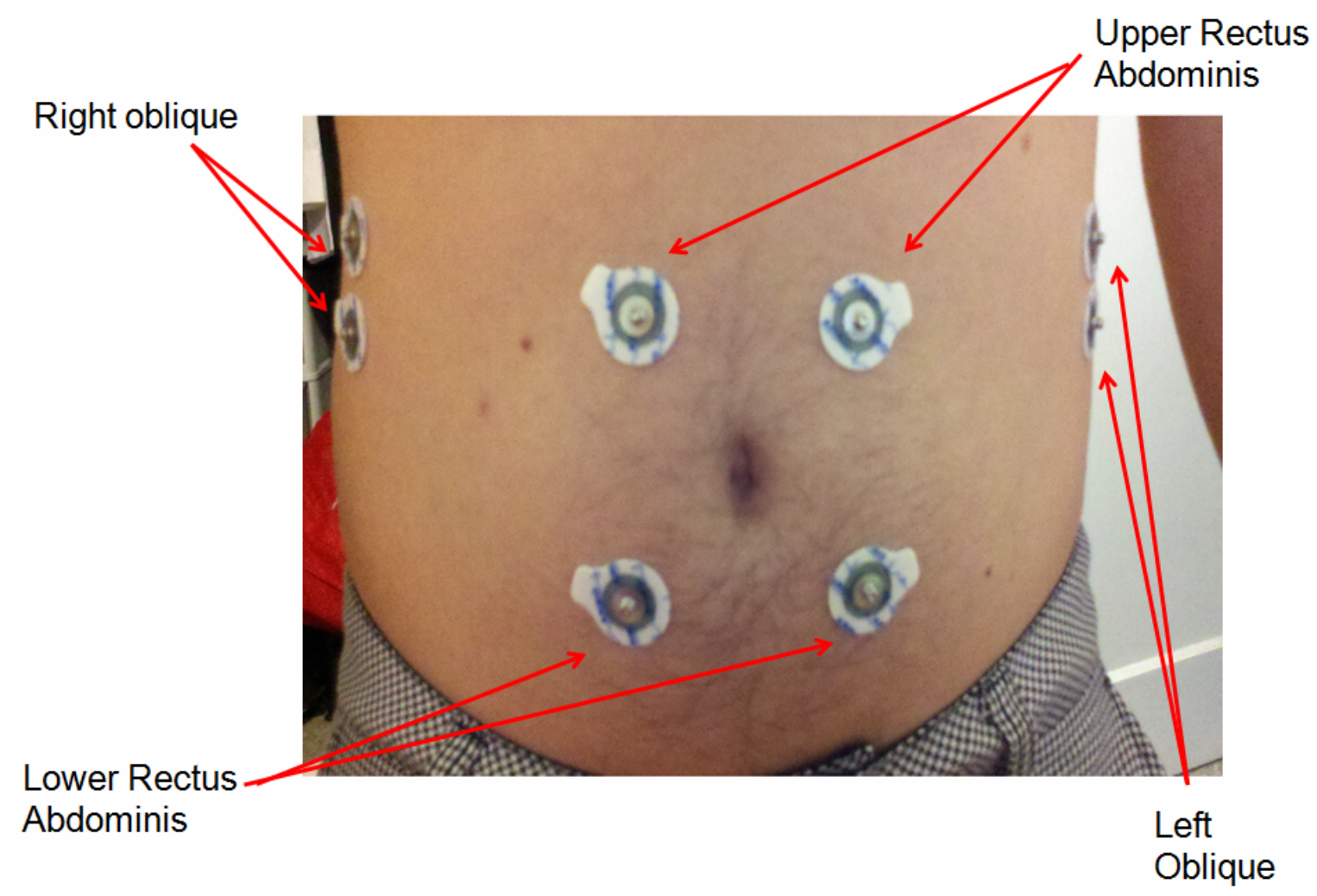

Figure 11: Electrode Placement

To determine if the electrodes were placed in the correct location there are several things that can be done. First of all it is important that the top of the iliac crest is found to make sure that the electrodes are being placed over the external obliques. If you palpitate the skin this bone is very easy to find so the placement of these electrodes is directly above it. For the electrodes being placed over the rectus abdominis muscles it is also easiest to palpitate the skin. The muscles can usually be easily be felt by palpitating the skin unless there is a large amount of tissue on top of 
them. In some individuals it is possible to visualize these muscles which makes it easy for the electrode placement. Once all the electrodes are placed the computer can be checked to make sure that a signal is being received and changes relative to the subjects movement.

\section{Data collection}

Data was collected using the PowerLab 26T (Product \# ML856, AD Instruments) and Lab Chart 7.0. The PowerLab 26T is a data recording device made by $\mathrm{AD}$ Instruments. It can be used to measure various biological responses and input them into the computer software LabChart. LabChart is a software package that displays the data collected from the PowerLab and has features that can analyze the data or convert it into different formats [34].

The PowerLab 26T has an integrated dual Bio Amp meaning that it can record two biopotentials at one time. In this experiment four biopotential measurements were being taken at once, the right obliques, left obliques, upper rectus abdominis, and lower rectus abdominis. Because the Power Lab 26T can only record two biopotentials at a time, two setups were used in order to account for the four channels needed. Two PowerLab systems were connected to two different computers in order to record the data.

When the PowerLab is set up and connected the computer, each biopotential that is recorded is made into a channel in the LabChart Software. For the EMG data being collected the information the equipment collected was in milivolts. Through the LabChart software, the data can be manipulated by creating another channel. For this experiment each computer had two channels which consisted of the raw data, and 
two channels were set up that converted the raw data into the root mean squared (RMS).

The electrodes that are placed on the subject are easily connected to the PowerLab through the dual Bio Amp by using a five lead shielded Bio Amp cable and five shielded lead wires. The lead wires have snaps on the ends that easily snap onto the electrodes.

After the subject's EMG electrodes had been connected to the Power Lab they lay down on a yoga mat on the floor. They were asked to relax and a baseline EMG reading was taken for ten seconds. The subjects then performed a maximum voluntary contraction. Both the baseline and maximum voluntary contraction measurements were collected in order to normalize the data. For the maximum voluntary contraction the subjects were asked to lie with their knees bent like they were going to perform a sit up. Their upper body and feet were then restrained, and they were told to try to do a sit up pushing against the restraint for five seconds. The purpose of this measurement is to find out what the maximum amount of force is that the subject can exert from their abdominal muscles. The measurements taken from the various exercises can then be compared to this number to determine how much of the subject's muscle is being activated during the exercises.

The subjects then performed six abdominal muscle exercises. Three of the exercises were traditional floor abdominal exercises. These consisted of the abdominal crunch, the reverse crunch, and the full vertical crunch. These exercises were chosen because they worked a variety of the abdominal area with the abdominal crunch working more of the upper rectus abdominis, the reverse crunch working more 
of the lower rectus abdominis and the full vertical crunch working all the core muscles at the same time. The next three exercises were seated abdominal exercises: the torso twist, the seated crunch, and the seated abdominal bend down. These exercises were chosen for the same reason as the floor exercises with each of the exercises focusing on a specific area. The torso twist is known for working the obliques, the seated crunch was focused more on the rectus abdomins, and the seated abdominal bend down worked all of the abdomal muscles. One set of the seated exercises was done in a wheel chair on stable ground and another set was done on the wheel chair balance board.

While on the wheel chair balance board the exercises were slightly modified. During the torso twist the subject was asked to twist not only their body, but also the board under them to either the left or the right depending on the direction they were twisting. For the seated abdominal crunch and seated abdominal bend down the exercise was changed to have the subject start with the back of the board touching the ground and when they sat forward have the front of the board touch the ground. They were asked to keep the sides of the board off of the ground during this time. After they did their exercise forward they were asked to return the board to the original position with the back of it on the ground. Figures of these modifications can be seen in Figure 12. The top two figures are of the subject performing the torso twist and turning the entire board as she twisted from side to side. The bottom pictures are of both the seated crunch and the seated abdominal bend down. The first image is the starting position with the back of the board touching the ground. The middle image shows how the seated abdominal bend down is performed with the front of the board 
now touching the ground as the subject reaches across their body to touch their toes. The picture on the right is of the seated crunch with the front of the board touching the ground. After the seated abdominal bend down and the seated crunch are completed the board will be back in the starting position with the back of it touching the floor. Each exercise was done a total of five times with the start and end of each exercises noted in the LabChart software. 

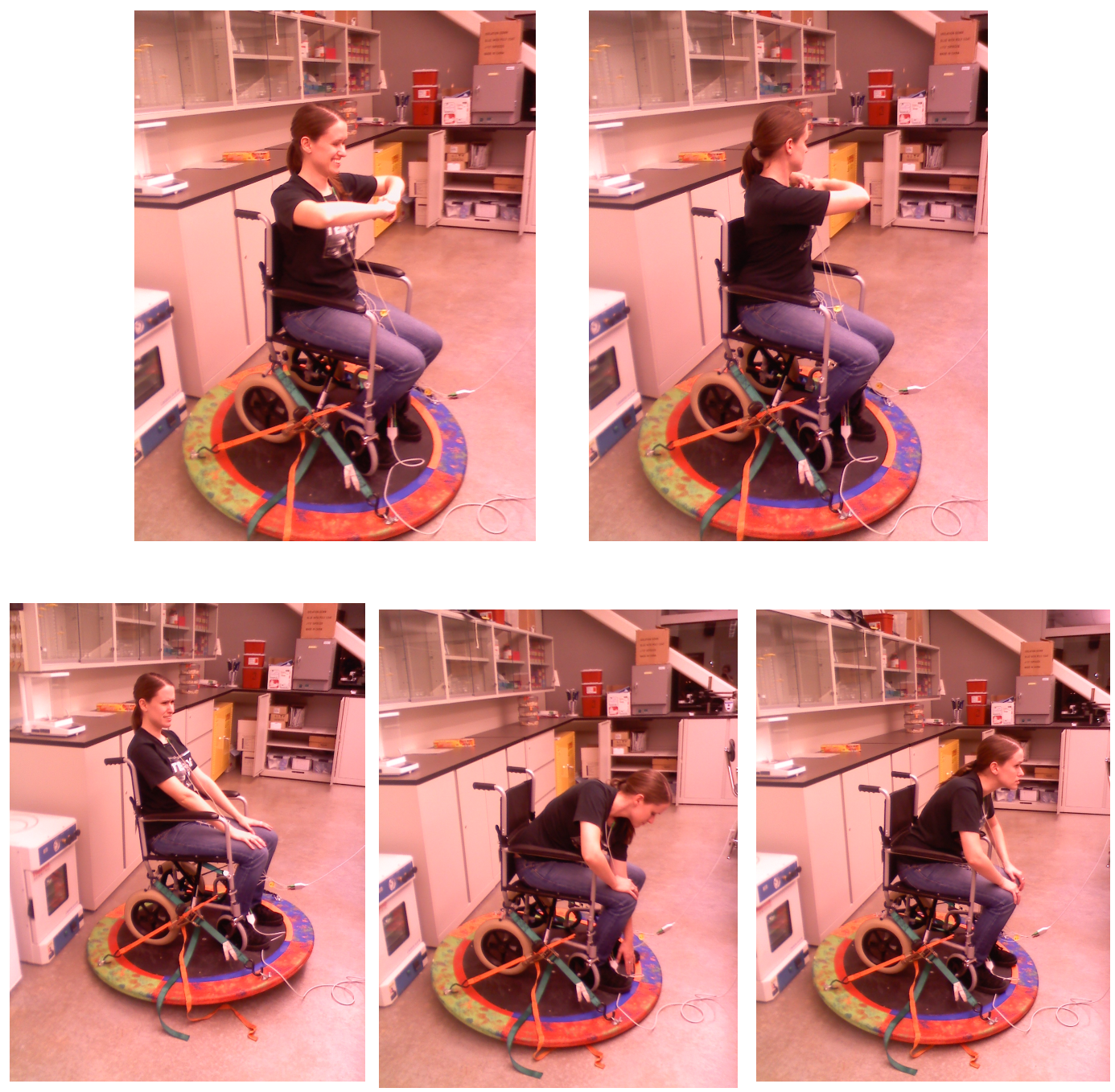

Figure 12: Modified Balance Board Exercises 


\section{Assumptions}

This study uses information collected from subjects so therefore there are some things that must be assumed when using this provided data. It is important that all data provided be as truthful as possible, but sometimes this is not always possible from the subjects. The following are the conditions that are assumed when collecting and analyzing the data.

Subjects will be asked if they have had any injuries within the past six months and if the information provided is false, it can throw off the results. The main injuries of concern are any to the core muscles. If this information is neglected it can lead to possible injury to the subject, as well as inaccurate results for the study. If the subject has had a muscle injury prior to the study in a muscle being observed, the muscle activation might be less than expected. This may be due to the subject unable to use the muscles because of potential pain. Also, if the muscle has not been used because of an injury it may have atrophied which can potentially lead to less force production.

The second assumption is that the users will participate in a given set of exercises and that the users will perform the exercises correctly. It is assumed that the subject will put his/her full amount of effort at all stages of the project to ensure that they are not working harder during some exercises compared to others. If the subject has in his/her mind that one exercise will work better than others, the subject may try harder on that exercise which will lead to misleading conclusions. To prevent this from occurring the participants will be asked to perform the exercises in various sequences; the exercises will be randomized, which should lead to more normalized results. The users will also be told how to do the exercises correctly and shown how 
to do them if they are still unsure, which will ensure that each subject is doing the exercise the same way.

\section{Data Analysis}

There are many ways to process the raw EMG signal from voluntary contractions. In this study the method used to process the EMG was to take the root mean square (RMS) of the data. This was done in the LabChart software and includes inverting the negative portions of the EMG by squaring the whole signal. The whole signal is then averaged and then the square root is calculated. By doing this, the individual spikes are smoothed out and the course of changing activity is much clearer [21].

Data was analyzed using a combination of LabChart Reader and MatLab. In LabChart Reader, the data files were opened and the start and end time points for each exercise was recorded. Data points were then collected at every 0.01 second. The RMS data was then put into a Notepad file that could be run through MatLab.

A MatLab Code, seen in Appendix $\mathrm{C}$, was written to analyze the data into the mean EMG reading for each exercise repetition. This was done by first reading the Notepad file into MatLab. Fourteen different inputs were collected from the main screen after the program was running. First the program asked for the start and stop time points when the subject was performing the baseline measurements. Next the start and stop time points were inputted for the maximum voluntary contraction, and finally the start and end time points for each repetition of the given exercise were entered. 
The program then calculated how many time points were in each selected time period by taking the end time point and subtracting the start time point and adding one. The sum of all the EMG data during those time points was then taken and divided by the total number of time points in that given section. This value was the calculated average muscle activation during the specified exercise for the given time period.

The next thing that was calculated was the percent change from baseline. The percent change from baseline was calculated by taking the absolute value of the muscle activation minus the baseline value. This value was then divided by the baseline value and multiplied by 100 . The equation for the percent change can be seen in Equation 1.

$\%$ Change $=\frac{\mid \text { muscle activation }- \text { baseline } \mid}{\text { baseline }} \times 100$

It was important to calculate the percent change from baseline in order to normalize the data from one user to another. By finding how much the muscle force changed from the baseline value the values for all the subjects can then be compared. Without normalizing the data there is no way to compare the data from one subject to another because even if one value is a lot higher than another one subject may have started at a higher value to begin with. By normalizing the values what is being compared is how much the values changed for each subject.

The Matlab code then calculated the fraction of the muscle activated. This was done to determine how much of the subject's muscles were actually being used 
during the various exercises. This was calculated by dividing the measure muscle force for the various exercises by the maximum contractile force. This was calculated again as a way to normalize the data from one subject to another. A flow chart of the data analysis process can be seen in Figure 13. 

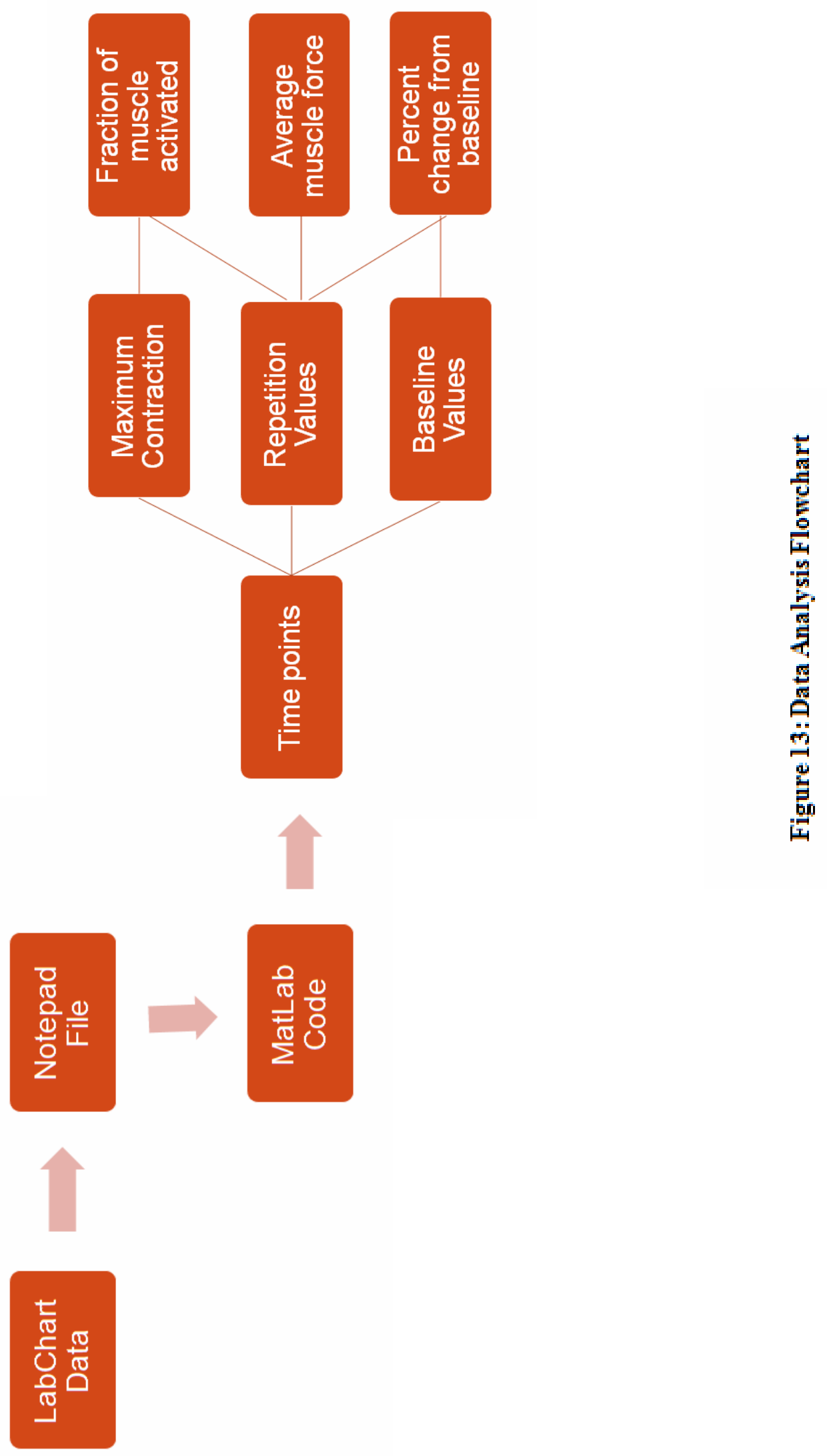


\section{Statistics}

Minitab 16 Statistical Software was used to perform the statistical analysis on the data collected. The data analyzed was the percent change from baseline and compared all the variables in the study. The different exercises, the type of exercise meaning floor, stable, or unstable, and the muscle being measured were all taken into account.

Individual value plots were created to compare the percent change in baseline for the type of exercise, the muscle recorded, and the exercise performed. This was used to help determine what values were the most variable to determine what values should be compared next. The individual value plots plot all of the data points which makes it easy to determine where to proceed with the statistical analysis because it is easy to visualize what data stands out from the rest of the group.

A series of one way ANOVA tests were then run to compare all of the collected. One way ANOVA tests are a easy way to compare multiple average values to determine if there is statistical significance between them. This test will only tell you if there is a difference however, it will not tell you which values are different. The first test compared the different muscle groups for each type of exercise, floor, stable, and unstable. The Tukey method was used to determine what group was statistically significant if any. The Tukey method will determine what values in the one way ANOVA test are statistically different from each other. The next series of ANOVA tests compared the stable and unstable exercises together, floor and 
unstable, and floor and stable. The last test compares the different muscle groups between the exercises.

One way ANOVA tests were used to compare all the collected data. The data used for the statistical test was the percent change from baseline. 


\section{Chapter 4: Results}

This section provides the data that was analyzed in this experiment. The information from the statistical tests that were run along with the data that was collected using MatLab can be found here as well as in Appendix D.

\section{Collected Data}

Data was collected from the subject through surface EMGs. This data was collected in a program called LabChart and was then exported into a notepad file. The notepad file was then analyzed by MatLab to gather the relevant information. The data focused on in the analysis is the percent change from baseline values. These values are the normalized values for each individual so that the collected data can be compared between subjects. The complete analyzed data set can be found in Appendix D. The complete data set includes a summary of the average muscle activations, the percent change from baseline, and the fraction of the activated muscle compared to the maximum contractile force.

Table 2 includes the average values for all ten subjects percent change from baseline of the different exercises broken down into the different muscle groups investigated. Each exercise has the average value for each of the four muscles that were examined in the experiment, the left oblique, lower rectus abdominis, right oblique, and upper rectus abdominis. The highest percent change seen in the table is from the seated abdominal bend down on the unstable surface. 
Table 2: Average Percent Change from Baseline for All 10 Subjects (\%)

\begin{tabular}{|c|c|c|c|c|}
\hline & \multicolumn{4}{|c|}{$\%$ Activation Change from Baseline } \\
\hline & $\begin{array}{l}\text { Left } \\
\text { Oblique }\end{array}$ & $\begin{array}{l}\text { Lower Rectus } \\
\text { Abdominis }\end{array}$ & $\begin{array}{l}\text { Right } \\
\text { Oblique }\end{array}$ & $\begin{array}{l}\text { Upper Rectus } \\
\text { Abdominis }\end{array}$ \\
\hline $\begin{array}{l}\text { Abdominal } \\
\text { Crunch }\end{array}$ & 389.02 & 473.50 & 668.92 & 313.09 \\
\hline Reverse Crunch & 402.29 & 743.13 & 1309.56 & 361.65 \\
\hline $\begin{array}{l}\text { Full Vertical } \\
\text { Crunch }\end{array}$ & 209.28 & 767.26 & 926.19 & 259.44 \\
\hline $\begin{array}{l}\text { Torso Twist } \\
\text { Stable }\end{array}$ & 283.69 & 426.19 & 1970.79 & 289.22 \\
\hline $\begin{array}{l}\text { Seated Crunch } \\
\text { Stable }\end{array}$ & 275.29 & 375.00 & 1115.04 & 354.81 \\
\hline $\begin{array}{l}\text { Sitting Abdominal } \\
\text { Bend Down } \\
\text { Stable }\end{array}$ & 367.00 & 1381.40 & 2701.26 & 776.43 \\
\hline $\begin{array}{l}\text { Torso Twist } \\
\text { Unstable }\end{array}$ & 254.27 & 267.77 & 2337.45 & 332.00 \\
\hline $\begin{array}{l}\text { Seated Crunch } \\
\text { Unstable }\end{array}$ & 249.15 & 397.26 & 4020.00 & 158.25 \\
\hline $\begin{array}{l}\text { Seated Abdominal } \\
\text { Bend Down } \\
\text { Unstable }\end{array}$ & 487.37 & 923.39 & 4810.93 & 456.31 \\
\hline
\end{tabular}

\section{Statistical Tests}

Two main types of statistical tests were performed. Individual value plots were created in order to see at a glance what outliers there were and one way ANOVA tests were run to determine any statistical significance. Tukeys method was run with the ANOVA test to determine which of the variables was statistically significant.

Three different individual value plots were created in order to see at a glance if there was any correlation between the type of exercise, the muscle groups, or the exercises themselves. These can be seen below in Figure 14. 
A. Type of Exercise

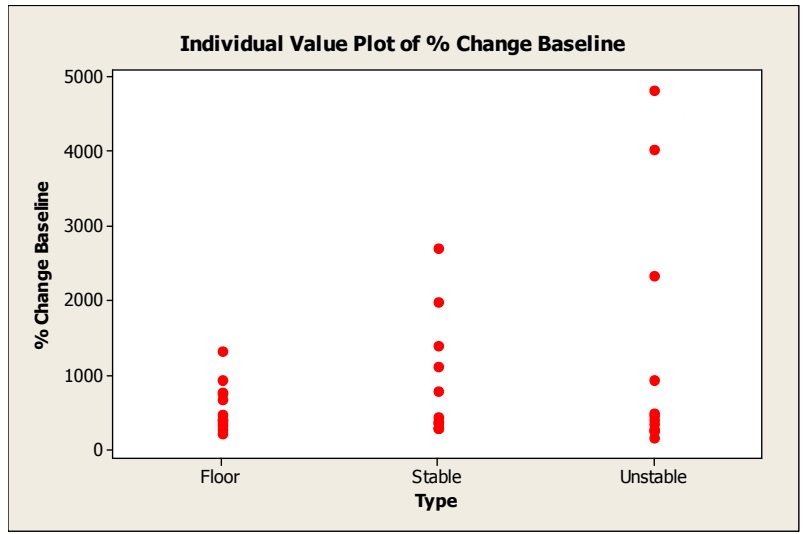

B. Muscle

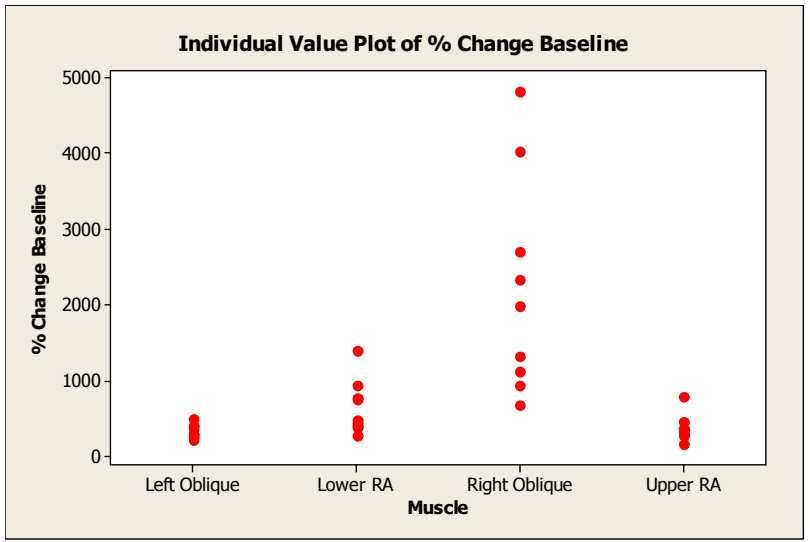

C. Exercise

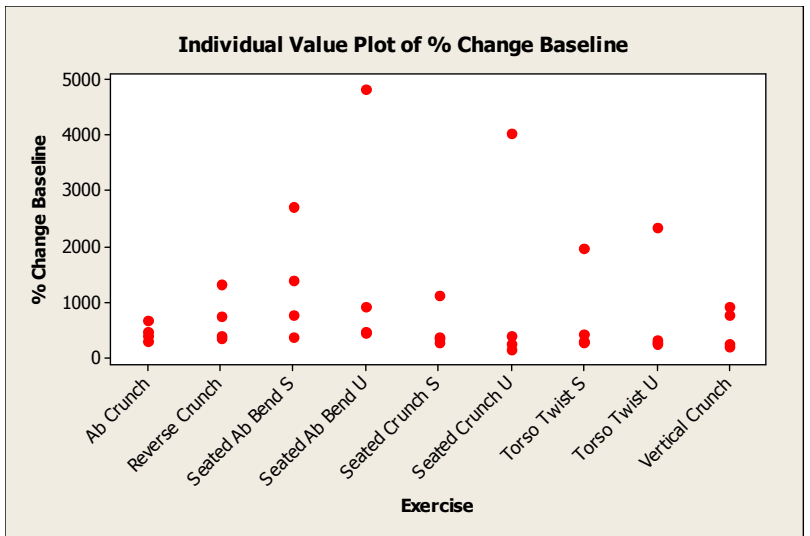

Figure 14: Individual Value Plots of the Percent Change From Baseline 
The individual value plots in Figure 14 plot all the data found in Table 2. For the Graph A, all of the data points for all four muscle groups were plotted depending on the type of exercise that was performed - floor, stable, and unstable. This made it easy to visualize that some groups, floor exercises, had a much smaller range of values for the percent change from baseline while others, unstable exercises, had a much larger range of values. Graph B took the data from Table 2 and plotted all of the individual points for the different muscle groups and Graph $\mathrm{C}$ graphed each individual exercise separately. In the graph there are four points for each exercise and those represent the four different muscle groups that were examined.

The first graph, Graph A, is an individual value plot of the percent change compared to the type of exercise performed - floor, stable, and unstable. From this graph it is clear that the type of exercise that caused the highest percent change from baseline was that on an unstable surface. Graph B is of the percent change from baseline compared between the different muscles. From this graph we can see that the right oblique consistently produced the highest percent change from baseline. Graph $\mathrm{C}$ is showing the percent change from baseline for each exercise that was performed. The highest percent change from baseline for this graph is for the seated abdominal bend down on the unstable surface. In all three graphs the highest percent change from baseline value corresponded to the seated abdominal bend down on an unstable surface for the right oblique. This value for the percent change from baseline was $4810.9 \%$.

A one - way ANOVA test was used to determine if there were differences seen between the different muscle groups for each type of exercise - the floor, 
unstable, and stable. In the comparison of the floor exercises to the percent change from baseline for the different muscle groups, a p value of 0.009 was found meaning that there was statistical significance in the data. Since an ANOVA test only shows if there is significance and does not show what the difference is, a Tukey Method was performed. The Tukey Method was used to determine which group was statistically different and in this test it was the right oblique muscle. In the comparison of the stable exercises for each muscle group of the percent change from baseline, a p value of 0.017 was found showing that there was again statistical signifigance. When the Tukey Method was performed it was again found that the difference was in the right oblique muscle. For the unstable exercises a p value of 0.001 was found showing that there was also a statistical difference. The Tukey Method run on this data again showed that the difference was the right oblique. These graphs can be found in Figure 15.

In a series of one - way ANOVA tests comparing the stable and unstable exercises together no statistical significance was found in the percent change from baseline values. When the unstable values for the various exercises were compared to the floor exercises there was again no statistical difference; however, the mean value of the percent change was always higher in the unstable platform exercises. There was also no statistical difference between the stable and floor exercises; however, in some instances the mean value for the stable percent change value was less than that of the floor exercise. 
A. Floor Exercises : $p=0.009$

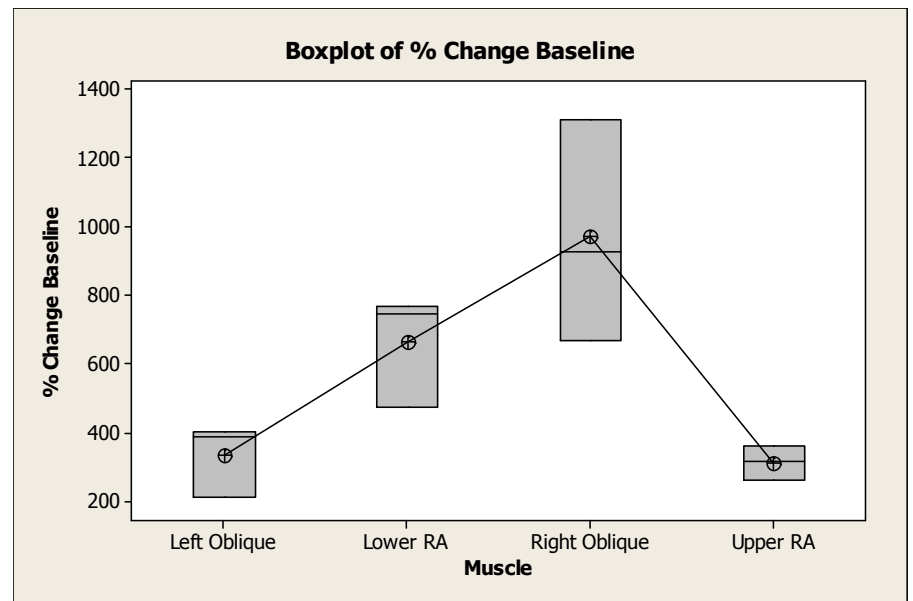

B. Stable Seated Exercises: $p=0.017$

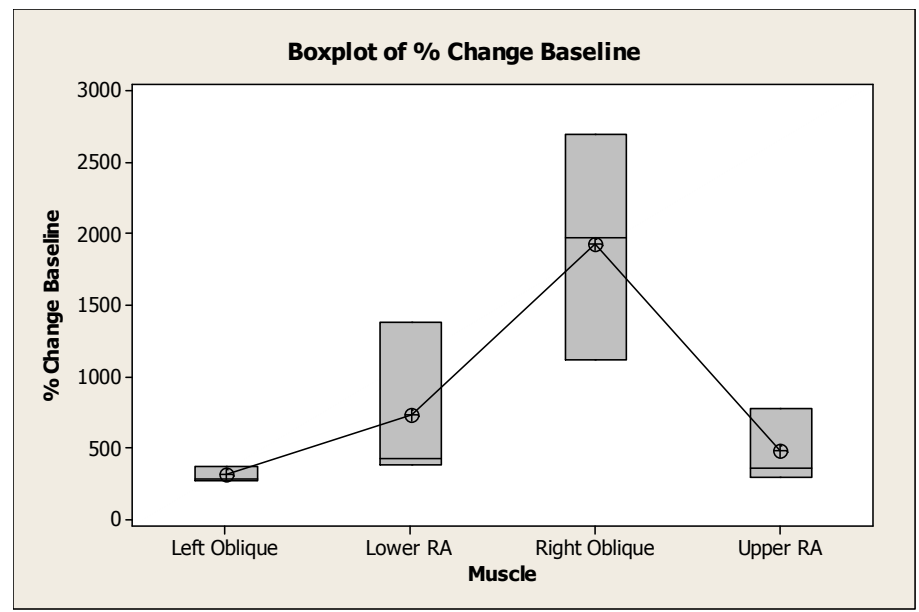

C. Unstable Seated Exercises: $p=0.001$

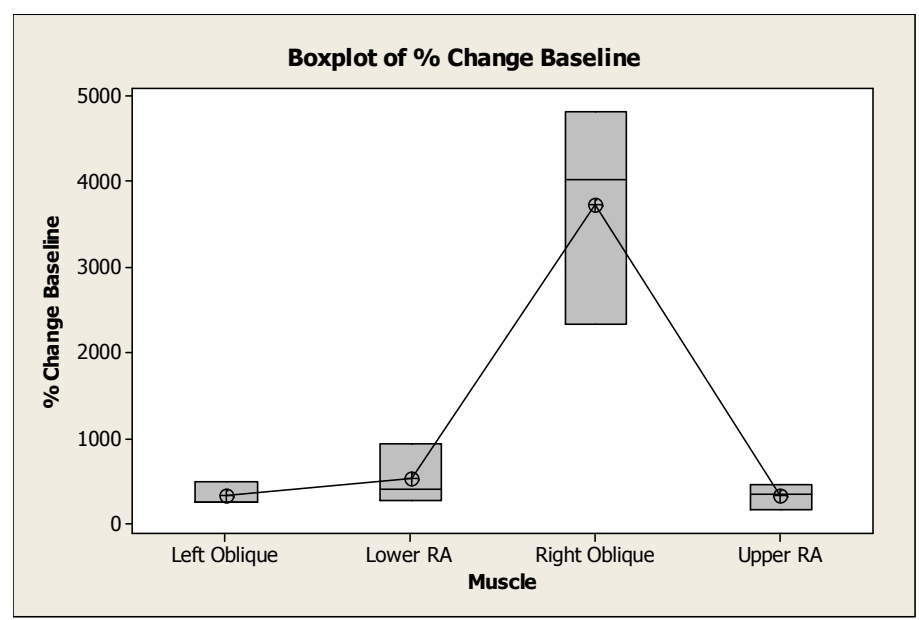

Figure 15: ANOVA Test of Muscle Activation 
Another series of ANOVA tests was done in order to compare the individual muscle groups between the exercises. This was done to determine if different muscles were being activated during the different type of exercises - floor, stable, and unstable. This is of importance because if changing from a stable platform to an unstable platform can work a different group of muscles more it could aid in a better exercise routine when aiming to work out certain muscles.

When comparing the right obliques of all the floor exercises and the stable and unstable seated crunch, the unstable seated crunch was found to be statistically higher than the floor exercises or the stable seated crunch. There was a statistically significant different with a $\mathrm{p}$ - value of 0.027. A graph for this test can be seen in Figure 16. This graph is a box plot of the percent change from baseline for the different types of exercises during the seated crunch and all the floor exercises. The floor and stable values are fairly close to each other however, the unstable value is much higher on the graph. This shows visually how different the unstable percent change from baseline was for the seated crunch in the right oblique and all the floor exercises for the right oblique. 


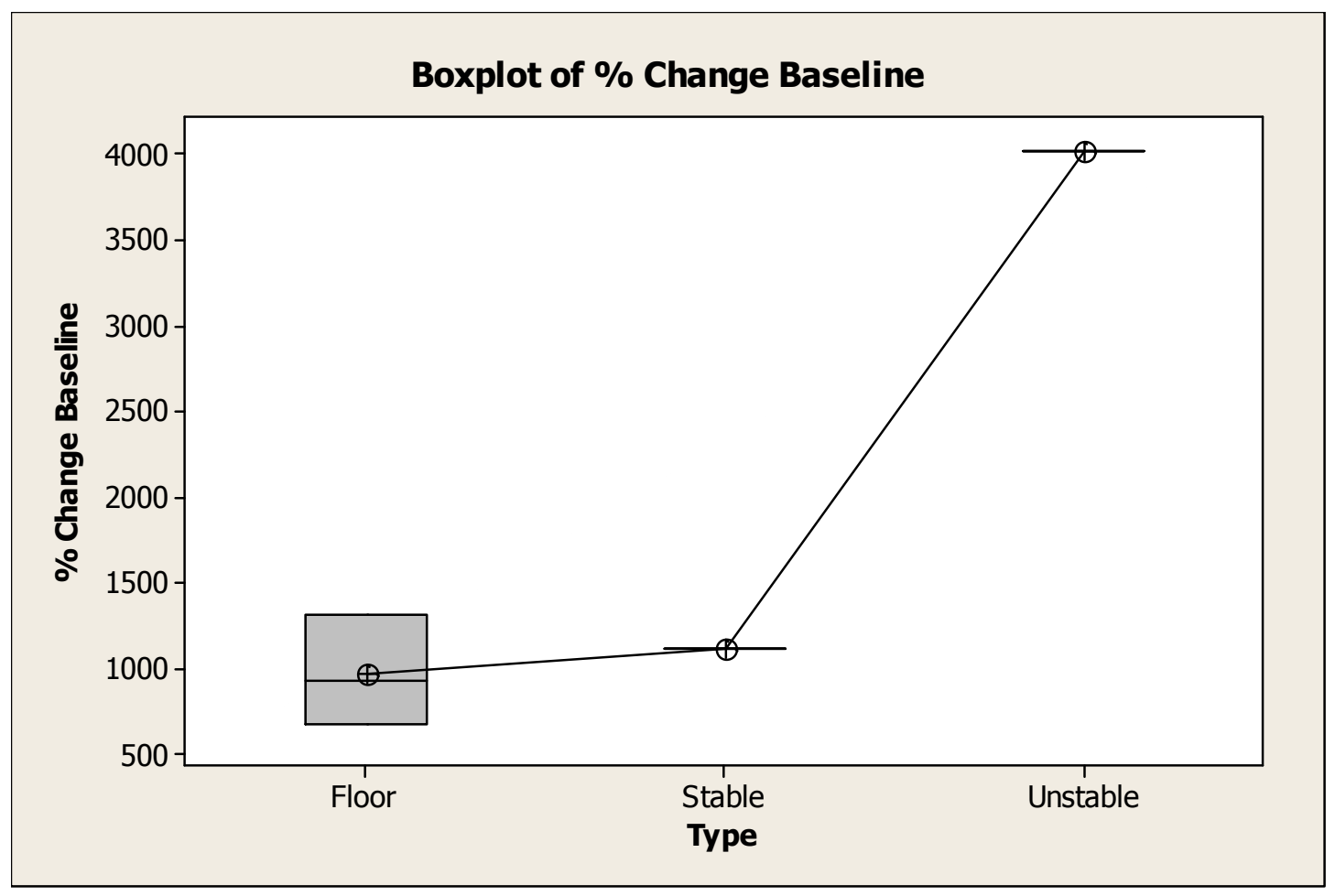

Figure 16: Seated Crunch Right Oblique and Floor Exercise Right Oblique Percent Change from Baseline

$\mathrm{p}$ value $=0.027$

In this same series of tests, the seated abdominal bend down for the right oblique also showed statistical significance, with a $\mathrm{p}$ - value of 0.018 . The unstable value was statistically different from the floor however it was not statistically different from the stable (Figure 17). There was no statistically significant difference between the stable and floor 


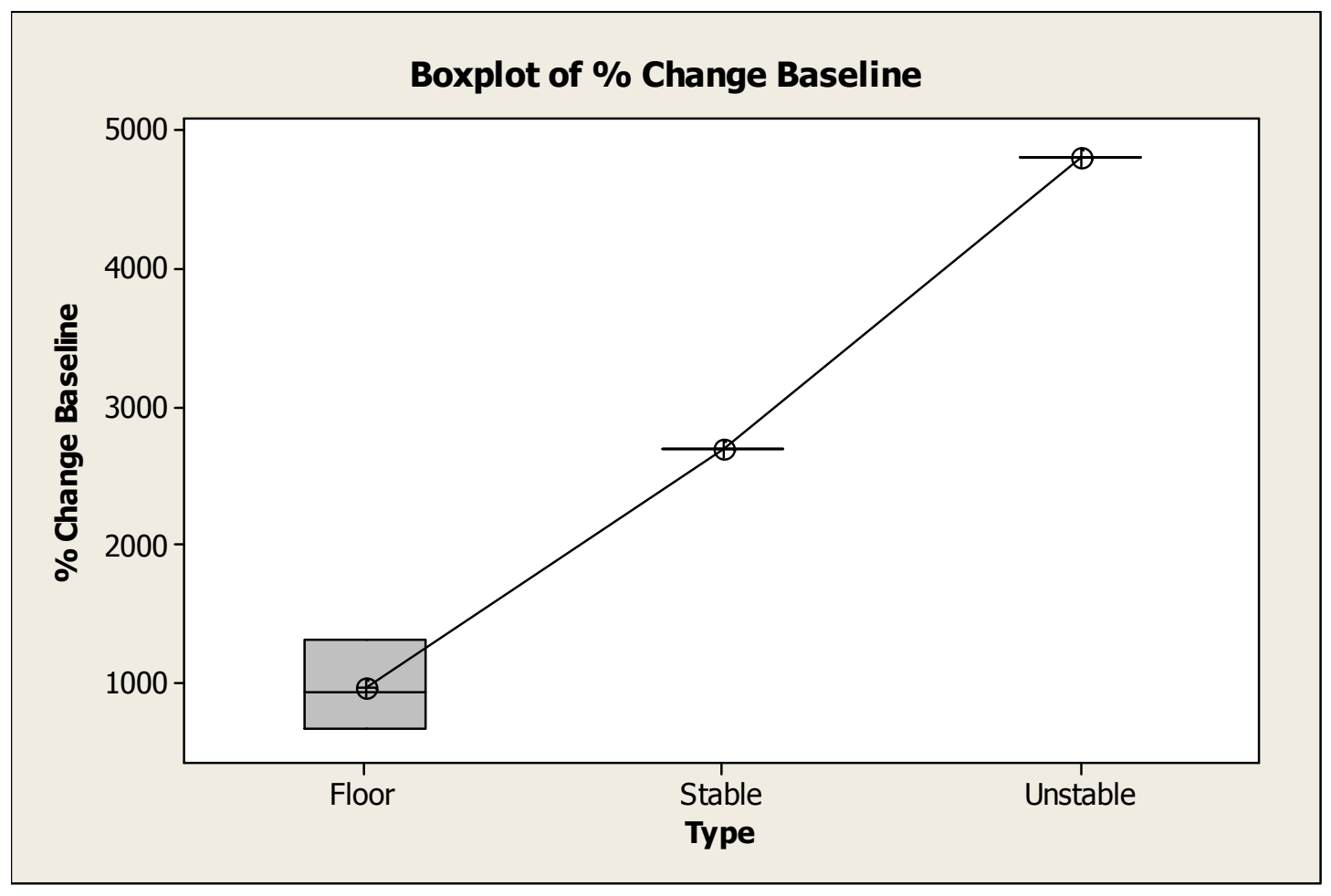

Figure 17: Seated Abdominal Bend Down Right Oblique's Percent Change $\mathrm{p}$ value $=0.018$

The only other muscle group that had statistical significance in the muscle group compared to the percent change was also in the sitting abdominal bend down for the upper rectus abdominis. This resulted in a $\mathrm{p}$ - value of 0.031 with the stable exercise being the percent change different from the unstable and the floor exercise, which can be seen in Figure 18. 


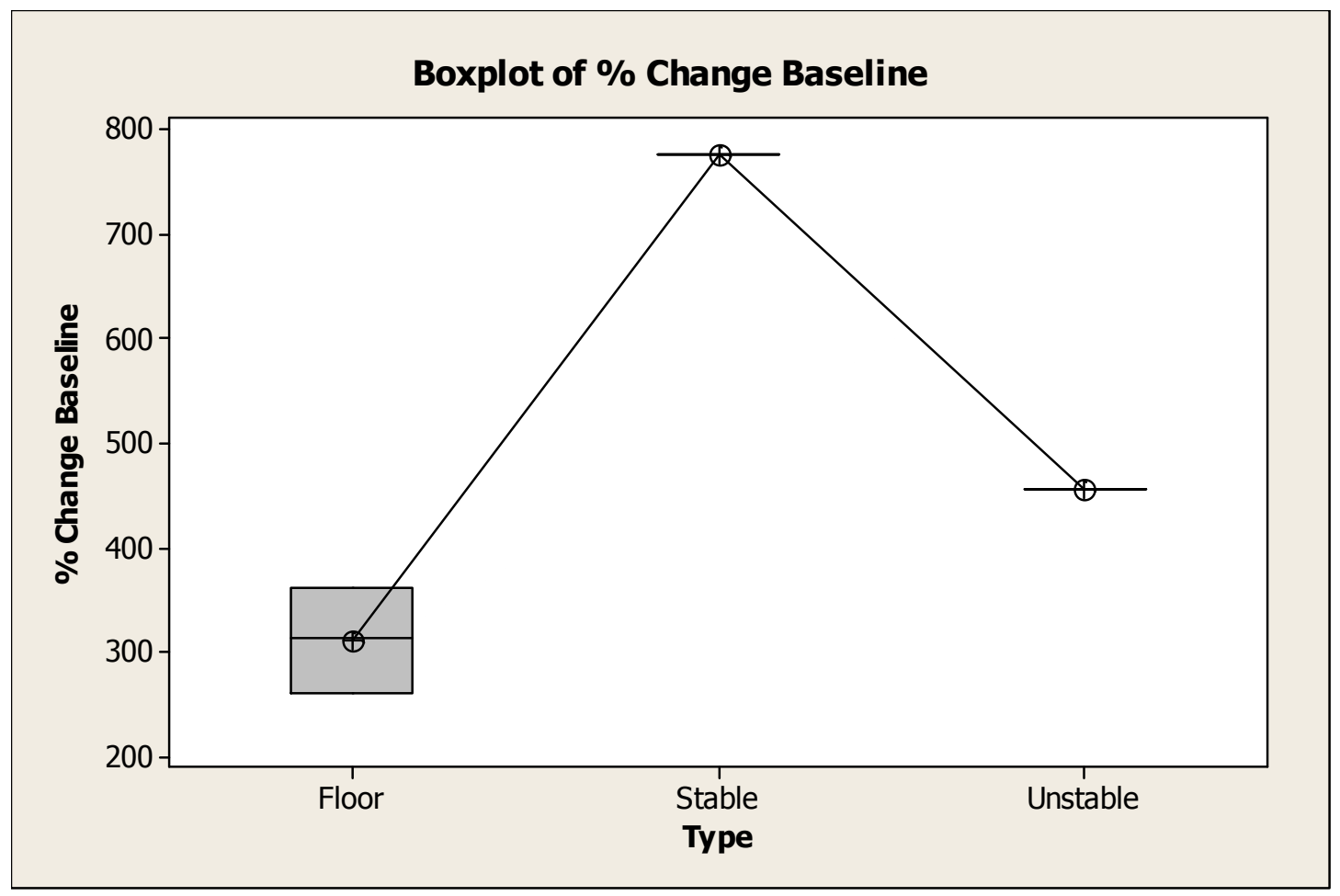

Figure 18: Seated Abdominal Bend Down Upper Rectus Abdominis Percent Change

$\mathrm{p}$ value $=0.031$ 


\section{Chapter 5: Conclusion}

\section{Discussion of the Results}

The individual value plots give a visual of how the data compares to each other. The graphs show that the unstable exercises, the right obliques, and the unstable seated abdominal bend down have the highest values from all the data. These plots are a visual representation of all the data found in Table 2 to show how it relates to itself. From this data it is clear that the floor exercises have a much smaller range in vales for the percent change in baseline compared to the unstable surface values.

The one - way ANOVA test comparing the muscle activation between each type of exercise - floor, stable, and unstable showed that there was a statistically significant difference between the muscle groups during the exercises in each case. From the graphs in Figure 15 it is clear that the right obliques in each exercise were the highest activated muscle. This is not exactly what was expected because many of the exercises used focused mainly on the rectus abdominis muscles, except for the torso twist and seated abdominal bend down which included more of the oblique muscles.

One reason that this muscle group could have been activated so much more compared to another could be because of electrode placement. If there was better contact with the muscle under the skin on one side of subjects compared to others it could lead to higher values seen. Additionally, if the majority of the subjects were right handed it may lead to the right side of their body being stronger than the left.

With the results from the ANOVA test comparing the percent change values for the stable compared to unstable, stable compared to floor, and floor compared to 
unstable nothing was statistically significant between the values. The mean value for the percent change for the unstable platform however was always the highest. This shows that although the balance board does not cause the subject to create a muscle force that is statistically higher than that of the seated chair or traditional exercises, it is not causing the user to lose any muscle force production and if modifications are made to the board it could potentially create more muscle force production.

From the ANOVA test comparing just the muscle groups for each exercise to each other there was significance found in the seated crunch exercise and the sitting abdominal bend down for the right oblique on the unstable platform. Having a higher muscle force on the unstable platform is what we were expecting to find because in order to attempt to stay balanced more muscles must be engaged. The reasoning behind why these exercises caused a higher muscle force compared to the torso twist could be because during these exercises the user was trying to keep the board from tipping side to side. This would engage more oblique muscles. Also, if the chair was not exactly centered on the board it could lead to the subject needing to use more muscles in order to stay balanced.

The seated abdominal bend down stable percent change values being statistically different from the unstable and floor exercises in the upper rectus abdominis muscle was not expected. The stable values could have been higher due to how the exercise was performed on the board. It is a possibility that subjects were concentrating more on the board than on the exercise itself and might not have been pulling in their abdominal muscles all the way. Because the unstable values are not different from the floor exercises however, this test just shows that this particular 
exercise can create a higher force in the upper rectus abdominis on the stable ground in the seated position compared to the floor exercises or on the unstable platform.

From the data presented, it can be concluded that the balance board does not cause any negative effects in terms of abdominal muscle activation. In some cases it has been shown to increase the muscle activation. There were no cases where there balance board caused a decrease in the amount of muscle activation in comparison to the floor exercises. The highest values for any muscle group activated in the entire study was found to be on the balance board during the sitting abdominal bend down. This goes to show that the balance board shows promise as a tool for creating a higher abdominal muscle force reaction while in the seated position.

\section{Summary}

This study was done to see if the wheelchair balance board could be used for more than just sensory stimulation for users in wheel chairs. The effect that the board has on the core muscles was examined in a functional study using ten able bodied individuals. The core muscles investigated were the upper and lower rectus abdominis and the right and left abdominal obliques. Surface electrodes were used along with the Power Lab system and LabChart software.

The test subjects participated in six different exercises: abdominal crunch, reverse crunch, full vertical crunch, torso twist, seated crunch, and sitting abdominal bend down. The seated exercises were performed on both a stable surface as well as on the balance board. Muscle activation was recorded and the RMS of each EMG signal was calculated. The average muscle activity for each repetition was recorded 
and then compared to the baseline value as well as to the subject's maximum contractile forces.

In each exercise the right abdominal oblique muscle had the highest force. There was a statistically significant difference found in the seated crunch and the seated abdominal bend down with the right oblique for the unstable surface being statistically higher in value than the traditional floor exercises. There were no cases when the unstable seated exercises were less than the traditional floor exercises and there was only one instance when the value was statistically significantly less than what was found in the seated stable exercises, which was the case in the seated abdominal bend down with the upper rectus abdominis muscle. This was not of great concern however because the stable floor exercise was also less than the seated abdominal crunch on a stable surface.

\section{Conclusion}

This study showed that the unstable platform can be used for more than just sensory stimulation. There were no negative effects of doing a variety of abdominal exercises while seated on the board and in some cases the amount of abdominal muscle activity was even increased above what was traditionally seen in floor abdominal exercises. When subjects were asked how they felt on the balance board compared to the stable ground they said that they felt they were doing more in order to move the board and themselves during the various exercises. The subjects also explained that on the floor the exercise was a lot faster and on the board it took more time. This extra time on the board during the exercise they felt made their abdominal muscles active for longer. With some advances in the board and possibly some other 
advances such as a better way to record the EMG signal, the wheel chair balance board could make a great tool for physical therapy and exercise for users in wheel chairs.

The main issue that was run into during this study was being able to get the board to balance. While on the board the subjects were having to focus on trying to stabilize the board while doing the exercise and since in some cases the board was unable to be balanced it made it difficult for the user to perform the exercise easily. Some work needs to be on the board to determine an easy way to automatically balance the board with the user on it. Even though the board was not able to be perfectly balanced each time it can be assumed that we would end up with the same result but with possibly different overall numbers.

This study was able to show a trend in the data even with these problems and with using a large variety of people in the study. The subjects had a wide range of physical activity level as well as differences in body shapes and muscle tone. This study showed that the wheelchair balance board is a novel way for people to get exercise that would not normally be getting it. People with different disabilities have different amounts of exercise abilities and therefore this study was a good representation of the various people who could be using the board.

\section{Future Work}

There are many ways that this work can be expanded on for further research. Modifications to the board can be done that will work different muscles or even enhance the muscle groups that were worked on. Different exercises can be 
examined or even created specifically for the board that could potentially aid users who have specific disabilities.

\section{Improvements to the Balance Board}

There are several improvements that can be made to the balance board that will make it easier to work with and even create more muscle activation for the user. One major improvement to the board would be to have a way to center the chair on the board. If this could be done it would help to make sure that all muscles are being worked the same and that the user is not have to over compensate for the board leaning more in one direction compared to another. By having a way to center the board it will take a lot of the guess work out of determining if the user is centered and could make doing the exercises easier while still working the muscles of interest.

Another modification that could be made to the balance board would be to create different degrees of tilt. The more tilt there is theoretically, the more muscle activation needed to move the board. If the amount of tilt could vary it would allow people to gradually work up to the more advanced degrees of difficulty.

A major improvement that needs to be made is the loading and unloading system. For this study, the method worked because it used able - bodied people who could be off of the chair while it was loaded on. It is possible to load someone in a wheel chair onto the board, however it take more than one person and the tie down method onto the board can take a while. If this could be changed to something simpler that only one person needed to help it would be a great improvement and ideally it would be ideal to create something that people could load themselves onto. 
Something else that could be looked into would be to see if adding weight to a side of the balance board will increase the muscle activity of the user. If the weight is increased on one side it could potentially lead to more muscle activity in the core muscles as they try to counteract the added weight force on one side of the board.

\section{Next Study}

There are various ways the next study could go. Ideally it would continue looking at the core muscles and maybe even look at some of the lower back muscles that are involved in the exercises such as the spina erecta muscles. These muscles are easily monitored with surface EMGs as well. By looking at more muscle groups the researcher could get a better idea of all the impacts that the board has on the subject. Also, during abdominal muscle exercises there is usually a lot of load placed on the back and if this load could be decreased in the lower back but increase the abdominal muscle activation it could provide a better exercise overall.

It would be useful to implement some sort of post exercise survey where subjects could rate how hard they felt the different exercises were. This could be useful to determine if the subjects are thinking they are working harder while on the unstable surface but not a large change in muscle activation is seen it could mean that there are different muscles involved in the exercise that need to be observed.

Another thing that needs to be looked into is possible designing exercises specifically for the board. Because the board is wider than the average wheelchair it could potentially have weights added to it. Even when doing the seated exercises that were chosen in this study they had to be modified to work on the board. If 
exercises could be created specifically for the board they could be tailored to make the board work against the user to create a higher muscle activation force.

A longer term study could also be helpful to see if there are any long term benefits of using the board. This study was short term and just looked at the EMG changes during one sitting. If subjects trained on the board over an extended period of time it would be interesting to see how the muscle adapt to the board and if there is an increase in muscle activity over time. A couple ways that this type of study could be accessed would be with surface electrodes to see if the muscle activation did improve over time as well as observations of subjects during their daily activities to see if they are able to perform tasks easier or if they were less out of breath. The subjects could also be asked to fill out a happiness survey to see if they are happier in their lives overall and are feeling better about themselves not only physically but psychologically also.

Finally, a study using actual users of wheel chairs should be done. This study was done as a functional study to make sure that the protocol would work and that there is no potential danger to the user. Because the device was designed for users in wheel chairs it would be interesting to see how their abdominal muscles would react to the unstable surface. Since this study used subjects who are able bodied they already have strong stabilizer muscles so that could be a reason that not a large difference was seen in the different exercise so performing a new study on users who do not have these muscles built up would be better. 


\section{References}

1. Physioball. 2011 March 6, 2011]; Available from: http://en.ledragomma.com/web/big-balls/physioball/.

2. Waehner, P. Ab Exercises. 2009 March 10, 2011]; Available from: http://exercise.about.com/od/abs/ss/abmoves1_2.htm.

3. Minium, M. Get Strong and Get Healthy. 2009 April 20, 2011]; Available from: http://cfo.footle.org/archive/200903

4. Bodywork, R. Erector Spinae Muscles. 2009; Available from: <http://www.deeptissue.com/learn/torso/erector.htm>

5. Ab Exercises. March 10, 2011]; Available from: http://www.appliedfitness.com/exercises/abs.aspx\#sittingab.

6. $\quad$ Sports Injury Treatment, Exercise ad Massage Products, UK. 20042004 March 6, 2011]; Available from:

https://www.physique.co.uk/dolc_product.asp?PCId=252.

7. MedicalLook. Abdominal Muscles. April 20, 2011]; Available from: http://www.medicalook.com/human_anatomy/organs/Abdominal_muscles.ht $\underline{\mathrm{ml}}$

8. Wobble Board, Bongo Board, Balance Balls from Fitter First. 2011 March 6, 2011]; Available from:

http://www.shopviewit.com/Merchant2/merchant.mvc?Screen=CTGY\&Categ ory_Code=fitterfirst.

9. Jay, C. Training Video - Alphabet and Leg Cycle. 2009 March 6, 2011]; Available from: http://www.coachjayjohnson.com/2009/02/training-videoalphabet-and-leg-cycle/.

10. Turning on The Light - The Balance Board. May 20, 2011]; Available from: http://www.turningonthelight.com/balance.html.

11. David G. Behm, E.J.D., Jeffrey M. Willardson, and Patrick M. Cowley, The use of instability to train the core musculature. Appl. Physiol. Nutr. Metab., 2010(35): p. 91-108.

12. BOSU stability balls for exercise. 2008-2009 May 19, 2011]; Available from: http://www.fitwithus.com/Articles/BOSU-Balls/]. 
13. Vera-Garcia, F.J., Grenier, S.G., and McGill, S.M., Abominal muscle response duing curl-ups on both stable and labile surfaces. Phys. Ther., 2000(80): p. 564-569.

14. Cosio-Lima, L.M., Reynolds, K.L., Winter, C., Paolone, V., and Jones, M.T., Effects of physioball and conventional floor exercises on early phase adaptations in back and abdominal core stablity and balance in women. $\mathrm{J}$. Strength Cond. Res., 2003. 17(4): p. 721-725.

15. Thompson, C.J., Cobb, K.M., and Blackwell, J, Functional training improves club head speed and functional fitness in older golfers. J. Strength Cond. Res., 2007. 21(1): p. 131-137.

16. Cressey, E.M., West, C.A., Tiberio, D.P., Kraemer, W.J., and Maresh, C.M., The effects of ten weeks of lower-body unstable surface training on markers of athletic performance. J. Strength Cond. Res., 2007. 21(2): p. 561-567.

17. Yaggie, J.A., and Campbell, B.M,, Effect of balance training on selected skills. J. Strength Cond. Res., 2006. 20(2): p. 422-428.

18. Clark, V.M. and A.M. Burden, A 4-week wobble board exercise programme improved muscle onset latency and perceived stability in individuals with a functionally unstable ankle. Physical Therapy in Sport, 2005. 6(4): p. 181187.

19. David G. Behm, E.J.D., Jeffrey M. Willardson, and Patrick M. Cowley, Canadian Society for Exercise Physiology position stand: The use of instability to train the core in athletic and nonathletic conditioning. Appl. Physiol. Nutr. Metab., 2010. 35: p. 109-112.

20. Saladin, K.S., Anatomy and Physiology: The Unity of Form and Function. 2009: McGraw Hill Science Engineering.

21. ADInstruments, S.o., Electromyography. 2010.

22. Sarver, J.J. EMG Analysis. April 19, 2011]; Available from: http://www.biomed.drexel.edu/labs/biomechanics/emg_analy.htm.

23. Systems, M.L. EMG Analysis Software. 2008 May 10, 2011]; Available from: http://www.emgsrus.com/software_emg_analysis.html.

24. Systems, B. Biopac Automated EMG Analysis. May 15, 2011]; Available from: http://www.biopac.com/FAQ-Details.asp?ID=124.

25. Price, J., UNDERSTANDING MUSCLES \& MOVEMENT: FROM THEORY TO PRACTICE. IDEA Fitness Journal. 7(8): p. 54-60. 
26. Kathryn M. Clark, L.E.H., ad Joy Sinyard, Electromyographic Comparison of the Upper and Lower Rectus Abdominis During Abdominal Exercises. Journal of Strenght and Conditioning Research, 2003. 17(3): p. 475-483.

27. McGill, C.T.A.a.S.M., Low back loads over a variety of abdominal exercises: searching for the safest abdominal challenge. Official Journal of the American College of Sports Medicine, 1996: p. 804-811.

28. Quinn, E. Basic Abdominal Crunch Exercise. 2009 [cited 2011 March 10, 2011]; Available from:

http://sportsmedicine.about.com/od/abdominalcorestrength1/qt/basic_crunch.h $\underline{\mathrm{tm}}$.

29. Waeher, P. Top 10 Most Effective Ab Exercises. 2011 March 10, 2011]; Available from: http://exercise.about.com/od/abs/ss/abexercises_7.htm.

30. Miller, S.-J. Seated Ab Exercises. March 10, 2011]; Available from: http://www.ehow.com/way_5407942_seated-ab-exercises.html.

31. Physiology, C.S.f.E. Par-Q. December 12, 2010]; Available from: http://www.csep.ca/cmfiles/publications/parq/par-q.pdf)

32. bio-medical. Kendall/ Tyco Arbo Disposable Electrodes. November 3, 2010]; Available from: http://www.csep.ca/cmfiles/publications/parq/parq.pdf)

33. Sorensen, E., Abdominal muscle activation during the isometric side support exercise: a comparison of stable and unstable surfaces: a thesis, in Kinesiology. 2007, California Polytechnic State University: San Luis Obispo.

34. Instruments, A. EMG Research. September 20, 2010]; Available from: http://www.adinstruments.com/solutions/research/EMG/. 


\section{Appendix A}

\section{Human Subjects Protocol}




\section{HUMAN SUBJECTS PROTOCOL APPROVAL FORM Cal Poly, San Luis Obispo}

All Cal Poly faculty, staff, and student research with human subjects, as well as other research involving human subjects that is conducted at Cal Poly, must be reviewed by the Cal Poly Human Subjects Committee for the protection of the human subjects, the researchers, and the University. Human subjects research is defined as any systematic investigation of living human subjects that is designed to develop or contribute to generalizable knowledge. While the ethical guidelines for research are applicable to classroom activities, demonstrations, and assignments, the Human Subjects Committee does not review classroom activities unless data will be collected and used in a systematic investigation.

Researchers should complete all items on this approval form and submit the appropriate number of copies of it, along with copies of a research protocol (containing the information detailed in the document Guidelines for Human Subjects Research Protocols), to the office of the current Chair of the Human Subjects Committee (Dr. Steve Davis, Bldg. 43, Rm. 353). Please feel free to attach an additional page if your responses to any of the items require more space. Your answers to the items on this form, as well as the research protocol, should be typed. The Committee will make every effort to respond to your submission within two to three weeks. Committee approval should be received prior to contacting prospective subjects and collecting data. Please read carefully Cal Poly's Policy for the Use of Human Subjects in Research prior to completing this application.

1. Date $\_\underline{11 / 18 / 2010}$

2. Title of the research project: Physical Therapy and Exercise for Users in Wheelchairs: A Study of Abdominal Muscle Activation

3. Type of research: Senior Project _ X_ Master's Thesis Faculty research Other

(Please describe)

4. Name(s) of researcher(s):

Other

A. Rebecca Campbell (principal investigator)

Dept. or Other Affiliation:_BMED___ Phone_408-234-3368

E-mail address:__campbel@ calpoly.edu

Position: Faculty_X_Student Other 
Dept. or Other

B. Affiliation Phone
Position: Faculty Student Other
(Please explain)

Dept. or Other

C. Affiliation Phone
Position: Faculty Student Other (Please explain)

Any additional researchers involved in the project should be listed with the descriptive information requested above on a separate sheet.

5. Faculty advisor, if applicable:

Dept. or Other

Lily Laiho Affiliation BMED Phone $\underline{805.756 .2172}$

E-mail address: $\underline{\text { laiho@ calpoly.edu }}$

Other thesis committee members if the research is a thesis:

Dept. or Other

A.

Affiliation Phone

Dept. or Other

B. Affiliation Phone

Dept. or Other

C. Affiliation Phone

6. Is there an external funding source for the project? ___ Yes _X_No If so, identify the funding source:

7. Is this a modification of a project previously reviewed by Cal Poly's Human Subjects Committee? Yes_X_No

If so, indicate the approximate date(s) of prior review(s).

8. Estimated duration of the project: _ January, 2011 to June, 2011 
9. Describe any risks (physical, psychological, social, or economic) that may be involved. See Specific Ethical Criterion \#1 in Cal Poly's Policy for the Use of Human Subjects in Research for a description of the types of risks.

There are very minimal risks associated with this study. Because we are using traditional physical therapy exercises, the risk of a muscle strain or injury is very minimal. Another risk is the possibility of a skin rash or skin irritation from the surface electrodes. This can occur if the person is allergic to the adhesive from the electrodes.

10. Indicate what measures will be taken to minimize risks. See Specific Ethical Criterion \#1 in Cal Poly's Policy for the Use of Human Subjects in Research for a discussion of strategies for minimizing risks.

To minimize risks, users will have to pass the Par Q test in order to participate. They will also be asked if they have had any injury in the past 6 months that the activities presented can aggravate. If they do not pass the Par Q or have had an injury they will be asked not to participate. In regards to the skin rash or irritation, subjects will be asked if they are allergic to any surface adhesives and if they are, they will again be asked not to participate. While there is no way to guarantee that they will not have an allergic reaction to the adhesive, these electrodes are standard of care use in hospitals as well as in class room settings here at Cal Poly, so the overall risk or chance of this happening is minimal.

11. Explain how subjects' confidentiality will be protected. See Specific Ethical Criterion \#5 in Cal Poly's Policy for the Use of Human Subjects in Research for a discussion of protection of confidentiality.

To protect the subjects confidentiality, all data will be recorded with a number attached to it. A key containing the subjects name and their corresponding number will be kept separate from the data that will have the subjects contact information in case follow up data is needed from that particular participant.

12. Describe any incentives for participation that will be used. See Specific Ethical Criterion \#2 in Cal Poly's Policy for the Use of Human Subjects in Research for a discussion of the use of incentives in research.

There will be no incentives provided to the subjects for participating in this study.

13. Will deception of subjects be involved in the research procedures? Yes_X_No

If so, explain the deception and how it will be handled. See Specific Ethical Criterion \#3 in Cal Poly's Policy for the Use of Human Subjects in Research for a discussion of the use of deception in research. 
14. Type of review requested: ___ Minimal review*

_X_Expedited review

Full review

See the section titled "Types of Review" in Cal Poly's Policy for the Use of Human Subjects in Research for a discussion of the criteria for minimal, expedited, and full reviews.

*The research protocol submitted for minimal review may be abbreviated but should contain sufficient information to support the conclusion that the project meets the criteria for minimal review.

\section{Signatures:}

\section{Primary Researcher}

Your signature below indicates that the information presented in this application (the approval form and research protocol) is accurate and that you have read, understand, and agree to follow the guidelines contained in Cal Poly's Policy for the Use of Human Subjects in Research.

Primary Researcher

$\underline{\text { Faculty Advisor (if applicable) }}$

Your signature below indicates that you have reviewed this research proposal, that you have agreed to supervise this research, and that you believe it is in compliance with Cal Poly's Policy for the Use of Human Subjects in Research.

Faculty Advisor 


\section{Human Subject Research Protocol}

\section{Title of Research}

Physical Therapy and Exercise for Users in Wheelchairs: A Study of Abdominal Muscle Activation

\section{Name and department of the primary investigator and faculty advisor}

- Rebecca Campbell - Biomedical Engineering

- Advisor Lily Laiho - Biomedical Engineering

\section{Purpose, benefits, hypothesis}

The purpose of this research is to improve the method of physical therapy for users in wheel chairs. If the method of physical therapy can be improved, it will allow for a faster recovery time from injury. A balance board has been created in order to create sensory stimulation for users in wheelchairs, and now we would like to see if the board can provide opportunities for physical therapy and exercise as well. People stand on balance boards in order to engage more muscle activity during physical therapy and so the same thought is being applied here to wheelchairs. If more muscles can be stimulated while doing the same exercises, it can lead to a faster recovery time. For my project I would like to show that using a balance board for wheel chairs during physical therapy and exercise will increase abdominal muscle activation.

\section{Methods}

Subjects

- Able bodied individuals

- Cal Poly students, faculty, staff and San Luis Obispo community members

- Participants will be selected depending on their answers to the Par Q survey given to them with their informed consent. This will determine if they are applicable to start a new exercise routine prior to checking with their physician.

- We will use up to 10 subjects, approximately half male and half female

- The expected age range of the subjects will be $18-40$ years old. Experimenters

- Rebecca Campbell

Materials and Procedures

- Materials to be used

- Standard practice will be used to attach surface EMG's

- Surface Electrodes (part \# 31.1245.21, Kendall) will be used to measure muscle activation in the abdominal area of the subjects by recording the electrical signal their activated muscles produce. 
- Abrasive Gel and Alcohol pads will be used to clean the area of the subject prior to electrode placement.

- Data Acquisition Software (Product\# ML856, AD Instruments) will be used to collect and analyze the data collected

- A mat on the ground will be used for the subject to perform traditional physical therapy and exercises on.

- A wheel chair will be used to perform physical therapy and exercises in both on and off the balance board.

- A Wheel Chair Balance Board will be used to provide the alternate surface to perform the physical therapy and exercises on while sitting.

- Location of study

○ Bld. 192 Room 328 Cal Poly State University, SLO

- Procedures

○ Subjects will be asked to fill out two surveys prior to starting the study as well as an informed consent form

- Informed Consent (Attached)

- Par Q Survey (attached)

- Background Questionnaire (attached)

- Based on the results of the Par Q study the subject will or will not be allowed to participate in the study

- Subjects will have surface electrodes applied to the skin in the abdominal area and one by the clavicle.

- Area will be cleaned with abrasive gel and alcohol prior to electrode placement

- 7 electrodes in total will be placed on the individual

- One electrode will be placed by the clavicle as a ground

- Two electrodes will be placed, one on the left side and one on the right, above the iliac crest on the same line as the umbilicus.

- Four electrodes will be placed in the abdominal region surrounding the umbilicus, two on the left side and two on the right. These will be placed $3 \mathrm{~cm}$ on either side of the umbilicus and then $5 \mathrm{~cm}$ superior to inferior to the umbilicus.

- The subjects will perform a maximum voluntary contraction of their abdominal muscles in order to be able to normalize all of the information. 


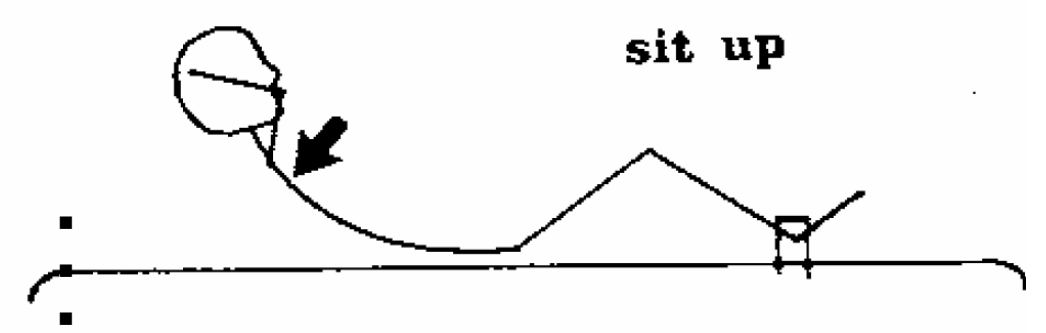

Picture from: Electromyographic Activity of the Abdominal and LowBack Musculature During the Generation of Isometric and Dynamic Axial Trunk Torque: Implications for Lumbar Mechanics

- The subject will be asked to lay on the floor. Their feet and shoulders will be restrained with a resistance band, allowing them to sit up to form a 30 degree angle.

- They will place their hands behind their head and asked to perform a sit up pushing as hard as they can against the restraint.

- They will be asked to hold this position for 3 seconds.

- The Subjects will then perform a series of traditional Physical therapy and abdominal exercises

- Abdominal Crunch

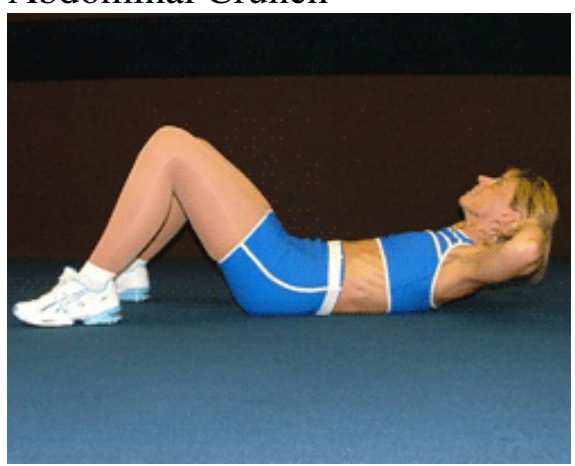

Picture from:

http://www.thedietchannel.com/images/michele_sile nce/sciatica/ab-crunch-B.gif

- Lie on your back, bend your knees, placing your hands on the sides of your head. 
- Contract your abs and flatten your lower back against the floor.

- Slowly lift your shoulder blades one or two inches off the floor.

- Exhale as you lift, keep your neck straight and chin up.

- Hold for a few seconds (don't hold your breath).

- Slowly lower while keeping your abs contracted.

- Repeat 5 times

- Reverse Crunch

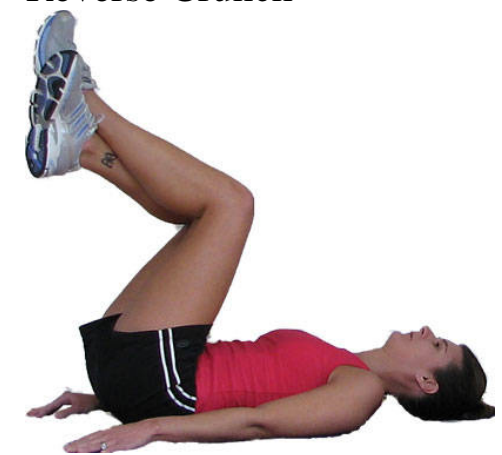

Picture from:

http://exercise.about.com/od/abs/ss/abexercises_7.h tm

- Lie on the floor and place hands on the floor or behind the head.

- Bring the knees in towards the chest until they're bent to 90 degrees, with feet together or crossed.

- Contract the abs to curl the hips off the floor, reaching the legs up towards the ceiling.

- Lower and repeat 5 times

- Full Vertical Crunch

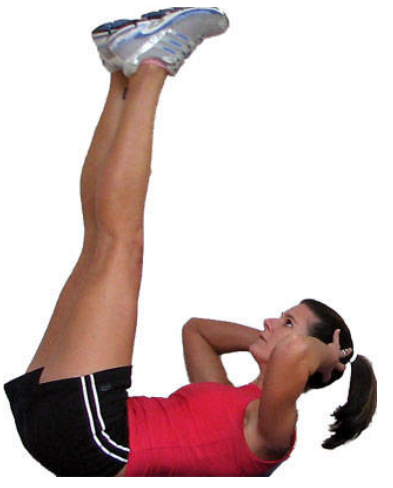


Picture from:

http://exercise.about.com/od/abs/ss/abexercises_8.h

tm

- Lie on your back and extend the legs up towards the ceiling.

- Place hands behind your head and contract the abs to lift the shoulder blades off the floor.

- At the same time, press the heels towards the ceiling, creating a 'u' shape with the torso.

- Lower down and repeat 5 times.

- Data from the electrodes will be recorded using the Data Acquisition Software and saved for further analysis.

- Then, on the stable ground, the participants will be asked to perform a set of physical therapy exercises while seated in the wheel chair.

- Torso Twist

Picture from:

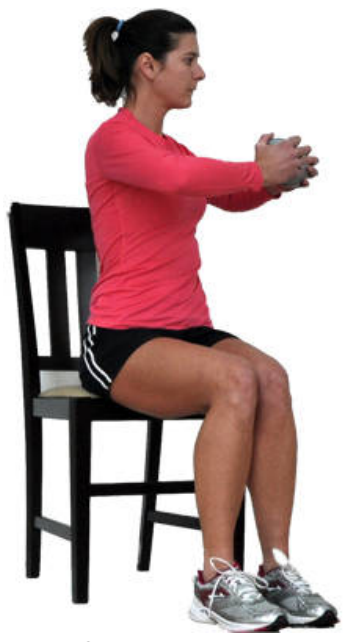

http://exercise.about.com/od/abs/ss/abmoves1_2.ht

$m$

- Keeping the hips and knees facing forward, rotate the torso to the right as far as you comfortably can. Focus on squeezing the muscles around your waist.

- Rotate back to center and then to the left, keeping the movement slow and controlled.

- Continue alternating sides 6 times 
- Seated Crunch

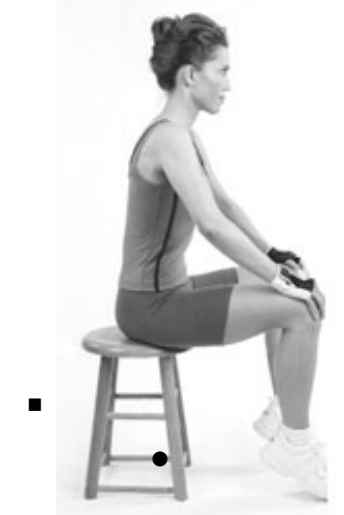

from:

http://www.appliedfitness.com/exercises/abs .aspx\#sittingab

- Sit in a chair with your back off the back rest. Sit up straight and look straight ahead with your chin level.

- Place your hands on your knees. Draw in your abs. Crunch your shoulders down as you bend at the ribs and exhale. Keep your chin lifted away from your chest as you crunch.

- Sit back up straight to complete the crunch.

- Repeat 5 times

- Sitting Ab Bend Down
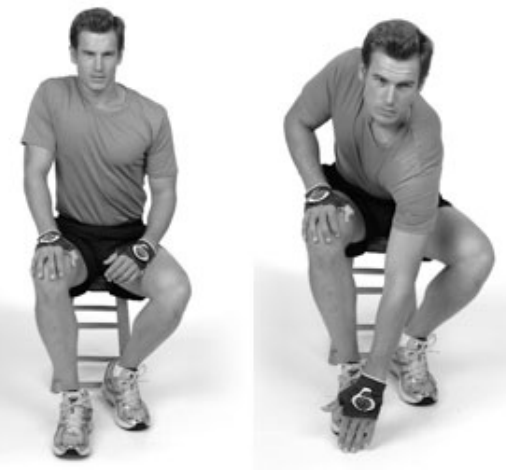

Picture from:

http://www.appliedfitness.com/exercises/abs.aspx\#s ittingab

- Place one hand on knee

- Apply downward pressure on knee while contracting ab muscles.

- With opposite hand reach across in font of foot at full contraction 
- Maintain pressure as you return to upright position

- Each rep should take 2-5 seconds.

- Repeat 6 times

- Data from the electrodes will be recorded using the Data Acquisition Software and saved for further analysis.

- The user will then be loaded onto the balance board and secured. From here they will be asked to perform the same exercises that they performed while in the wheel chair on the stable ground.

- Picture of user on the wheelchair balance board

-

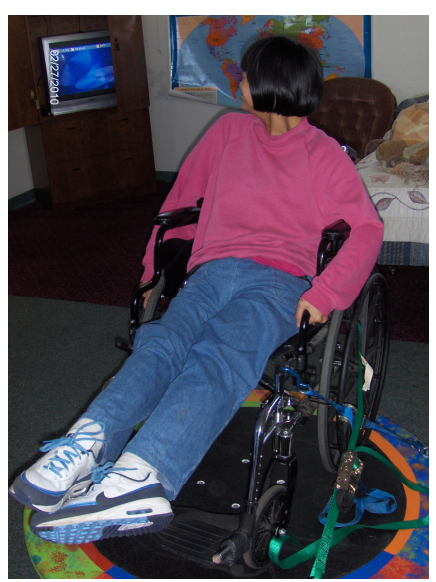

- Data from the electrodes will be recorded using the Data Acquisition Software and saved for further analysis.

- Debriefing of participants

- For the debriefing the subjects will be allowed to ask any questions they might have regarding the study. Additional information will be provided explaining the purpose of the study to them as well as thanking for their time. 


\section{Pre Study Questionnaire}

Please fill out this information prior to starting the study.

1) Age

2) Sex
a. Male
b. Female

3) Current activity level
a. None
b. Multiple times a week
c. Once a week
d. Once a month
e. Rarely

4) Any Injuries within the last 6 months?
a. Yes
b. No

If so explain

5) Are you allergic to any surface adhesives?
a. Yes
b. No

If so which ones? 
INFORMED CONSENT TO PARTICIPATE IN:

\section{Physical Therapy and Exercise for Users in Wheel Chairs: A Study of} Abdominal Muscle Activation

A research project on the effects of altering platform conditions (stable versus unstable) on the surface electromyography (EMG) abdominal muscle response during physical therapy exercises is being conducted by Rebecca Campbell in the Department of Biomedical Engineering at Cal Poly, San Luis Obispo.

The purpose of the study is to analyze the EMG muscle amplitudes of the abdominal muscles during physical therapy exercises under stable and unstable platform conditions to determine if differences exist. Data will be recorded using surface electromyography (EMG) on the abdominal muscles. This involves placing electrodes onto the skin which are used to record electrical activity of the abdominal muscles during the exercises. The skin preparation will be done by cleaning the area with alcohol prior to electrode placement.

You are being asked to take part in this study by completing the attached questionnaire, participating in the exercise trials, and completing a follow up survey. The exercise trials will involve doing a series of physical therapy exercises while on the stable ground, and then completing the same exercises on an unstable balance board platform.

Your participation will take approximately one to two sessions consisting of a maximum of one hour each. The second session will only be necessary if there is difficulty with data collection and analysis during the first session. Please be aware that you are not required to participate in this research and you may discontinue your participation at any time without penalty. You may also omit any items on the questionnaire(s) you prefer not to answer.

The possible risks associated with participation in this study include a skin rash or irritation and the possibility of muscle strain. If you should experience a skin rash or irritation or muscle, please be aware that you may contact the University Health Center at 805.756 .1211 or in Building 27 for assistance.

Your participation in this research is confidential. Neither your name or other information which could identify you will be used 
without your permission in reports of this research. Potential benefits associated with the study include the knowledge that you will be contributing to research in the area of abdominal exercises for users in wheel chairs.

If you have questions regarding this study or would like to be informed of the results when the study is completed, please feel free to contact Lily Laiho at 805.756.2172. If you have concerns regarding the manner in which the study is conducted, you may contact Dr. Steve Davis, Chair of the Cal Poly Human Subjects Committee, at 756-2754, sdavis@calpoly.edu, or Dr. Susan Opava, Dean of Research and Graduate Programs, at 756-1508, sopava@calpoly.edu.

If you agree to voluntarily participate in this research project as described, please indicate your agreement by completing and returning the attached questionnaire. Please retain this consent cover form for your reference, and thank you for your participation in this research.

Signature of Participant

Date

Signature of Researcher

Date 
(A Questionnaire for People Aged 15 to 69)

Regular physical activity is fun and healthy, and increasingly more people are starting to become more active every day. Being more active is very safe for most people. However, some people should check with their doctor before they start becoming much more physically active.

If you are planning to become much more physically active than you are now, start by answering the seven questions in the box below. If you are between the ages of 15 and 69 , the PAR-Q will tell you if you should check with your doctor before you start. If you are over 69 years of age, and you are not used to being very active, check with your doctor.

Common sense is your best guide when you answer these questions. Please read the questions carefully and answer each one honestly: check YES or NO.

\begin{tabular}{|c|c|c|}
\hline YES & No & \\
\hline$\square$ & $\square$ & $\begin{array}{l}\text { 1. Has your doctor ever said that you have a heart condition and that you should only do physical activity } \\
\text { recommended by a doctor? }\end{array}$ \\
\hline$\square$ & $\square$ & 2. Do you feel pain in your chest when you do physical activity? \\
\hline$\square$ & $\square$ & 3. In the past month, have you had chest pain when you were not doing physical activity? \\
\hline$\square$ & $\square$ & 4. Do you lose your balance because of dizziness or do you ever lose consciousness? \\
\hline$\square$ & $\square$ & $\begin{array}{l}\text { 5. Do you have a bone or joint problem (for example, back, knee or hip) that could be made worse by a } \\
\text { change in your physical activity? }\end{array}$ \\
\hline$\square$ & $\square$ & $\begin{array}{l}\text { 6. Is your doctor currently prescribing drugs (for example, water pills) for your blood pressure or heart con- } \\
\text { dition? }\end{array}$ \\
\hline$\square$ & $\square$ & 7. Do you know of any other reason why you should not do physical activity? \\
\hline \multicolumn{2}{|l|}{ If } & YES to one or more questions \\
\hline \multicolumn{2}{|l|}{ you } & $\begin{array}{l}\text { Talk with your doctor by phone or in person BEFORE you start becoming much more physically active or BEFORE you have a fitness appraisal. Tell } \\
\text { your doctor about the PAR-Q and which questions you answered YES. }\end{array}$ \\
\hline \multicolumn{2}{|c|}{ answered } & $\begin{array}{l}\text { - You may be able to do any activity you want — as long as you start slowly and build up gradually. Or, you may need to restrict your activities to } \\
\text { those which are safe for you. Talk with your doctor about the kinds of activities you wish to participate in and follow his/her advice. } \\
\text { - Find out which community programs are safe and helpful for you. }\end{array}$ \\
\hline
\end{tabular}

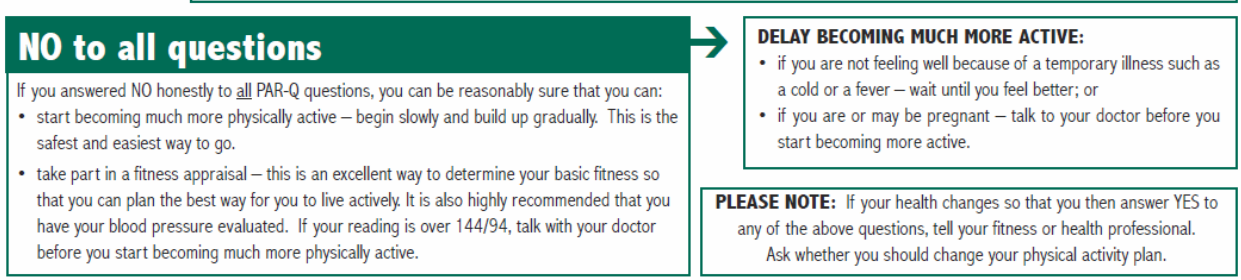

Informed Use of the PAR-Q: The Canadian Society for Exercise Physiology, Health Canada, and their agents assume no liability for persons who undertake physical activity, and if in doubt after completing this questionnaire, consult your doctor prior to physical activity

No changes permitted. You are encouraged to photocopy the PAR-Q but only if you use the entire form.

NOTE: If the PAR-Q is being given to a person before he or she participates in a physical activity program or a fitness appraisal, this section may be used for legal or administrative purposes.

"I have read, understood and completed this questionnaire. Any questions I had were answered to my full satisfaction."

NAME

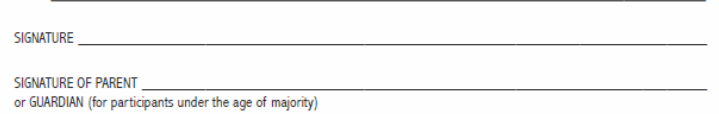

DATE

SIIGNATURE OF PAREM

WITNESS

\begin{tabular}{|l}
$\begin{array}{l}\text { Note: This physical activity clearance is valid for a maximum of } 12 \text { months from the date it is completed and } \\
\text { becomes invalid if your condition changes so that you would answer YES to any of the seven questions. }\end{array}$ \\
\hline
\end{tabular}


Appendix B

EMG Electrode Product Data

$\underline{\text { Sheet }}$ 


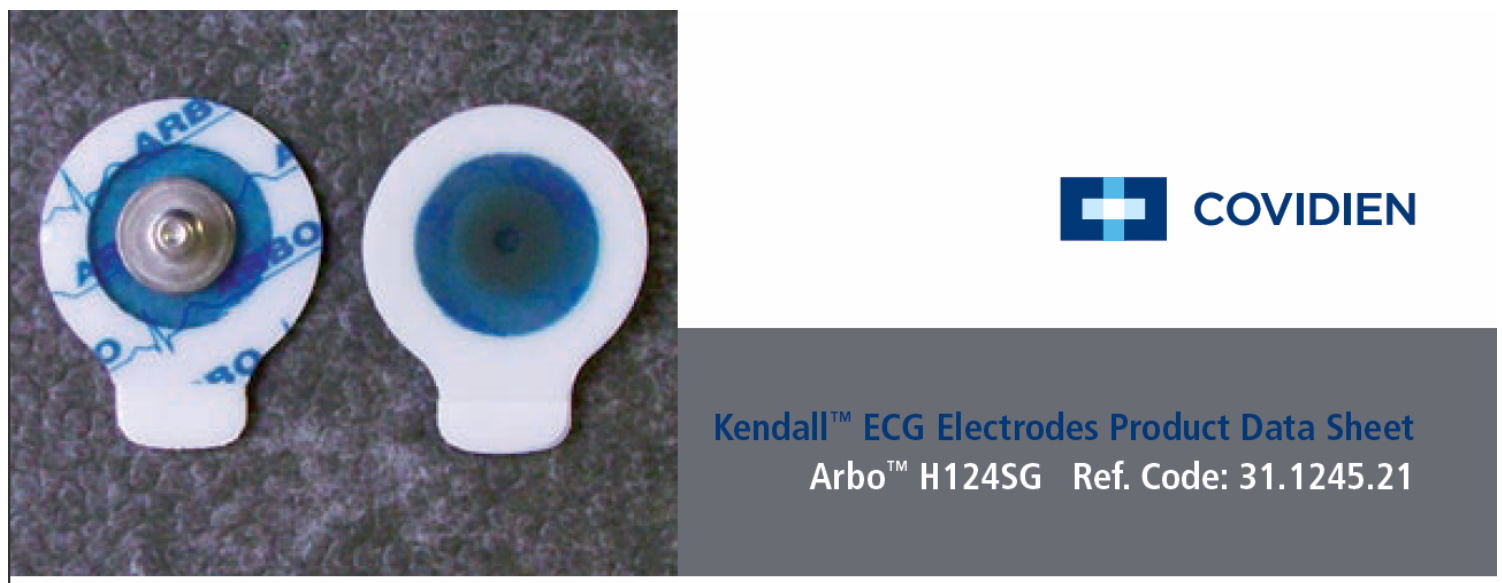

1. BASIC PRODUCT INFORMATION

Shape / size (excl. grip)

Total product surface (excl. grip)

Gel area

Adhesive area

Sensor area

Product thickness (adapter excluded)

Adapter

Integrated lead wire (length / colour)

2. MATERIALS INFORMATION

\section{Backing material}

Adhesive characteristics

Gel characteristics

Supporting / back label

Release liner

Sensor

Adapter / connector

Integrated lead wire jacketing

Integrated lead wire cord
5. PACKAGING

\begin{tabular}{lrrr} 
& $\mathrm{L} \times \mathrm{W} \times \mathrm{H}(\mathrm{mm})$ & Content (electrodes) & Material \\
Product packaging (pouch) & $220 \times 180$ & 50 & Paper / PE / Alu / PE \\
Department packaging (box) & $194 \times 194 \times 240$ & 500 & Paper cardboard \\
Transport packaging (carton) & $600 \times 400 \times 510$ & 6000 & Paper cardboard \\
& & & \\
6. BIOCOMPATIBILITY & & \\
\hline Test acc. to DIN ISO 10993 & & passed \\
LATEX content & & no
\end{tabular}

7. ENVIRONMENT (detailed information related to product and packaging see "Environmental Declaration")

Halogenated hydrocarbon content (e.g. PVC)

Phthalate derivatives content (e.g. DEHP)

RoHS directive

Polye Polyproplene fim (PP) tran hP Polymer Ag/AgCl coated Stainless steel

8. SHELF LIFE

Product shelf life in an intact, originally sealed packaging 24 months $@ 10 \ldots 30^{\circ} \mathrm{C}$

3. ELECTRICAL CHARACTERISTICS

(ANSI/AAMI EC 12, average measured before packaging)

ACZ I impedance (before defibrillation simulation)

DC offset voltage (before defibrillation simulation)

SDR (remaining potential after defibrillation simulation)

Slope (potential decline after defibrillation simulation)

CollN (combined offset instability and inner noise)

Bias current tolerance (DC offset voltage after DC loading)

\section{LEGAL STATUS}

CE Mark according to MDD 93/42/EEC

\section{SPECIAL FEATURES}

MRI compatibility ( $\leq 3 T)$

$X$-ray translucence

Peel off resistance, max. (from PE foil, $180^{\circ}, 50 \mathrm{~mm} / \mathrm{min}$, ASTM D1876)

$220 \mathrm{Ohm}$

$0.2 \mathrm{mV}$

$11 \mathrm{mV}$

$4 \mu \mathrm{V}$

$6 \mathrm{mV}$

Integrated abrader

Repositionability

no
no

$2.5 \mathrm{~N}$

$2.5 \mathrm{~N}$

no

\section{COVIDIEN}

\begin{abstract}
Disclaimer: Specifications and other information presented in this document are for information purpose only and do not provide any recommendation or advise of any kind. Data may differ from actual values quoted here and Tyco / Covidien does not make any warranties or representations to any characteristics. Subject to changes without notice.

COVIDIEN, COVIDIEN with logo and TM marked brands are trademarks of Covidien AG or an affiliate C 2008 Covidien AG or an affiliate. All rights reserved. 31124521e2008-10-06 TY0648 MED 2009 PM 0013
\end{abstract}




\section{Appendix C Matlab Code}




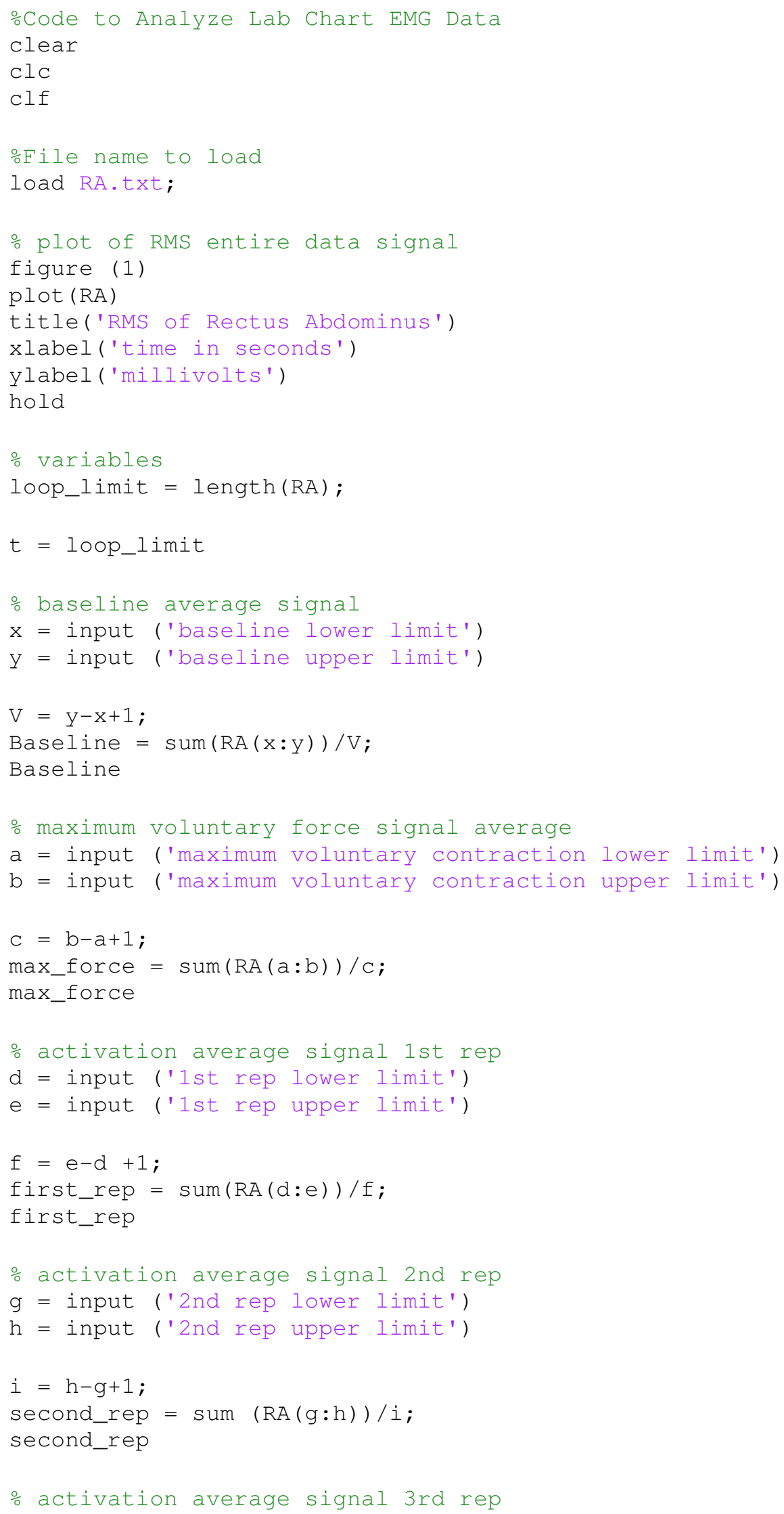




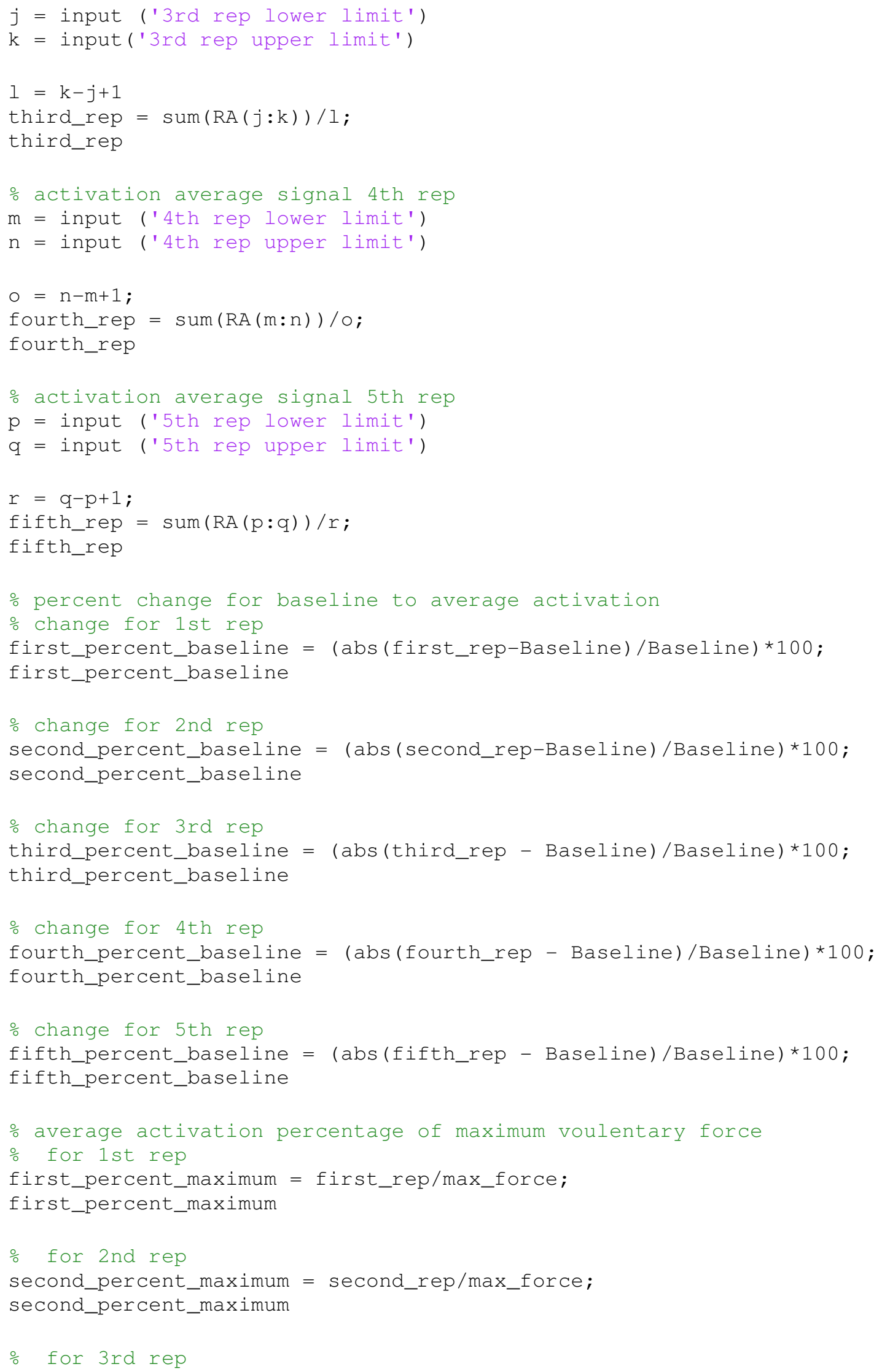


third_percent_maximum = third_rep/max_force;

third_percent_maximum

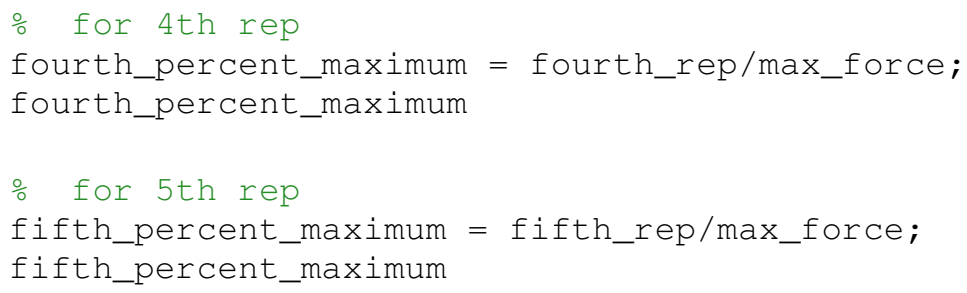




\section{Appendix D}

\section{Tables of Results}




\section{Average Muscle Response in mili-volts}

\begin{tabular}{|l|l|l|l|l|l|}
\hline & \multicolumn{5}{|c|}{ Average muscle response in mili-volts } \\
\hline & Left Oblique & $\begin{array}{l}\text { Lower Rectus } \\
\text { Abdominis }\end{array}$ & Right Oblique & $\begin{array}{l}\text { Upper Rectus } \\
\text { Abdominis }\end{array}$ \\
\hline $\begin{array}{l}\text { Abdominal } \\
\text { Crunch }\end{array}$ & 0.19 & 0.54 & 0.20 & 0.27 \\
\hline $\begin{array}{l}\text { Reverse } \\
\text { Crunch }\end{array}$ & 0.19 & 0.68 & 0.44 & 0.26 \\
\hline $\begin{array}{l}\text { Full Vertical } \\
\text { Crunch }\end{array}$ & 0.13 & 0.59 & 0.36 & 0.23 \\
\hline $\begin{array}{l}\text { Torso Twist } \\
\text { Stable }\end{array}$ & 0.16 & 0.51 & 0.72 & 0.17 \\
\hline $\begin{array}{l}\text { Seated Crunch } \\
\text { Stable }\end{array}$ & 0.14 & 0.34 & 0.42 & 0.21 \\
\hline $\begin{array}{l}\text { Sitting } \\
\text { Abdominal } \\
\text { Bend Down } \\
\text { Stable }\end{array}$ & & & & & 0.48 \\
\hline $\begin{array}{l}\text { Torso Twist } \\
\text { Unstable }\end{array}$ & 0.19 & 0.93 & 0.87 & 0.16 \\
\hline $\begin{array}{l}\text { Seated Crunch } \\
\text { Unstable }\end{array}$ & 0.14 & & 0.17 & & 0.83 \\
\hline $\begin{array}{l}\text { Seated } \\
\text { Abdominal } \\
\text { Bend Down } \\
\text { Unstable }\end{array}$ & 0.25 & 0.53 & & 1.50 & 0.19 \\
\hline
\end{tabular}




\section{Percent Change from Baseline of Muscle Activation}

\begin{tabular}{|c|c|c|c|c|}
\hline & \multicolumn{4}{|c|}{$\%$ Change from baseline of Muscle Activation } \\
\hline & Left Oblique & $\begin{array}{l}\text { Lower Rectus } \\
\text { Abdominis }\end{array}$ & Right Oblique & $\begin{array}{l}\text { Upper Rectus } \\
\text { Abdominis }\end{array}$ \\
\hline $\begin{array}{l}\text { Abdominal } \\
\text { Crunch }\end{array}$ & 389.02 & 473.50 & 668.92 & 313.09 \\
\hline $\begin{array}{l}\text { Reverse } \\
\text { Crunch }\end{array}$ & 402.30 & 743.13 & 1309.56 & 361.65 \\
\hline $\begin{array}{l}\text { Full Vertical } \\
\text { Crunch }\end{array}$ & 209.28 & 767.26 & 926.19 & 259.44 \\
\hline $\begin{array}{l}\text { Torso Twist } \\
\text { Stable }\end{array}$ & 283.69 & 426.19 & 1970.79 & 289.22 \\
\hline $\begin{array}{l}\text { Seated Crunch } \\
\text { Stable }\end{array}$ & 275.29 & 375.00 & 1115.04 & 354.81 \\
\hline $\begin{array}{l}\text { Sitting } \\
\text { Abdominal } \\
\text { Bend Down } \\
\text { Stable }\end{array}$ & 367.00 & 1381.40 & 2701.26 & 776.43 \\
\hline $\begin{array}{l}\text { Torso Twist } \\
\text { Unstable }\end{array}$ & 254.27 & 267.79 & 2337.45 & 332.00 \\
\hline $\begin{array}{l}\text { Seated Crunch } \\
\text { Unstable }\end{array}$ & 249.15 & 397.26 & 4020.00 & 158.25 \\
\hline $\begin{array}{l}\text { Seated } \\
\text { Abdominal } \\
\text { Bend Down } \\
\text { Unstable }\end{array}$ & 487.37 & 923.39 & 4810.93 & 456.31 \\
\hline
\end{tabular}




\section{Response Force Fraction of Maximum Contraction Force}

\begin{tabular}{|c|c|c|c|c|}
\hline & \multicolumn{4}{|c|}{ Fraction of Maximum Contraction Force } \\
\hline & Left Oblique & $\begin{array}{l}\text { Lower Rectus } \\
\text { Abdominis }\end{array}$ & Right Oblique & $\begin{array}{l}\text { Upper Rectus } \\
\text { Abdominis }\end{array}$ \\
\hline $\begin{array}{l}\text { Abdominal } \\
\text { Crunch }\end{array}$ & 1.71 & 1.55 & 1.37 & 2.88 \\
\hline $\begin{array}{l}\text { Reverse } \\
\text { Crunch }\end{array}$ & 1.68 & 1.93 & 3.02 & 5.18 \\
\hline $\begin{array}{l}\text { Full Vertical } \\
\text { Crunch }\end{array}$ & 1.30 & 1.82 & 1.57 & 2.60 \\
\hline $\begin{array}{l}\text { Torso Twist } \\
\text { Stable }\end{array}$ & 1.48 & 1.22 & 3.05 & 1.76 \\
\hline $\begin{array}{l}\text { Seated Crunch } \\
\text { Stable }\end{array}$ & 1.10 & 1.34 & 1.91 & 2.45 \\
\hline $\begin{array}{l}\text { Sitting } \\
\text { Abdominal } \\
\text { Bend Down } \\
\text { Stable }\end{array}$ & 1.53 & 4.26 & 4.39 & 4.12 \\
\hline $\begin{array}{l}\text { Torso Twist } \\
\text { Unstable }\end{array}$ & 1.35 & 1.26 & 3.67 & 1.55 \\
\hline $\begin{array}{l}\text { Seated Crunch } \\
\text { Unstable }\end{array}$ & 1.20 & 1.96 & 5.71 & 1.54 \\
\hline $\begin{array}{l}\text { Seated } \\
\text { Abdominal } \\
\text { Bend Down } \\
\text { Unstable }\end{array}$ & 2.33 & 3.35 & 6.90 & 8.37 \\
\hline
\end{tabular}

